\title{
Isolating Added Mass Load Components of CPAS Main Clusters
}

\author{
Eric S. Ray ${ }^{1}$ \\ MRI Technologies (JETS), Houston, TX, 77058
}

\begin{abstract}
The current simulation for the Capsule Parachute Assembly System (CPAS) lacks fidelity in representing added mass for the $116 \mathrm{ft} \mathrm{D}_{0}$ ringsail Main parachute. The availability of 3-D models of inflating Main canopies allowed for better estimation the enclosed air volume as a function of time. This was combined with trajectory state information to estimate the components making up measured axial loads. A proof-of-concept for an alternate simulation algorithm was developed based on enclosed volume as the primary independent variable rather than drag area growth. Databases of volume growth and parachute drag area vs. volume were developed for several flight tests. Other state information was read directly from test data, rather than numerically propagated. The resulting simulated peak loads were close in timing and magnitude to the measured loads data. However, results are very sensitive to data curve fitting and may not be suitable for Monte Carlo simulations. It was assumed that apparent mass was either negligible or a small fraction of enclosed mass, with little difference in results.
\end{abstract}

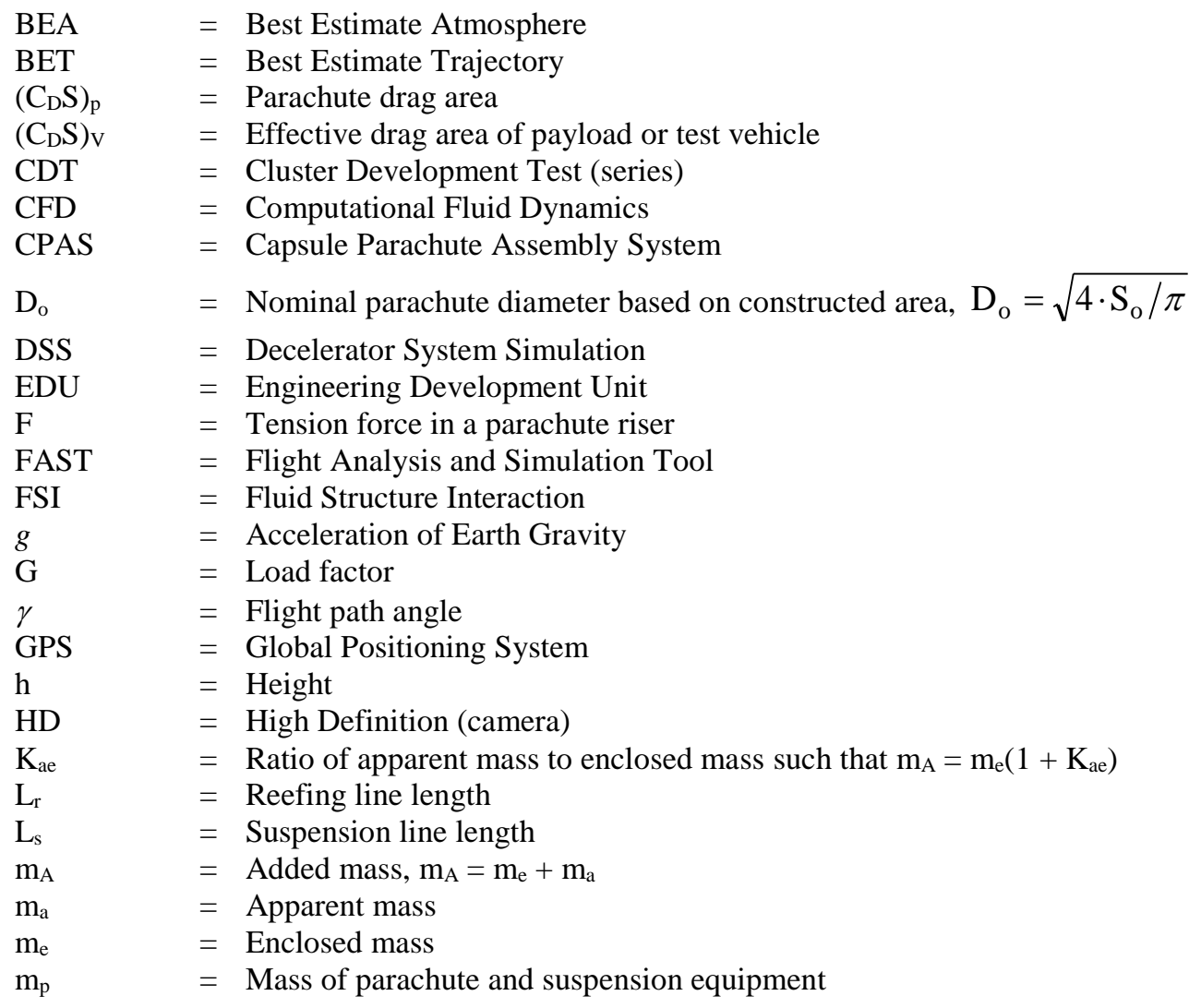

\footnotetext{
${ }^{1}$ Analysis Engineer, Aerosciences, Flight Dynamics and GN\&C, 2224 Bay Area Blvd, Houston, TX, AIAA Senior
} Member. 


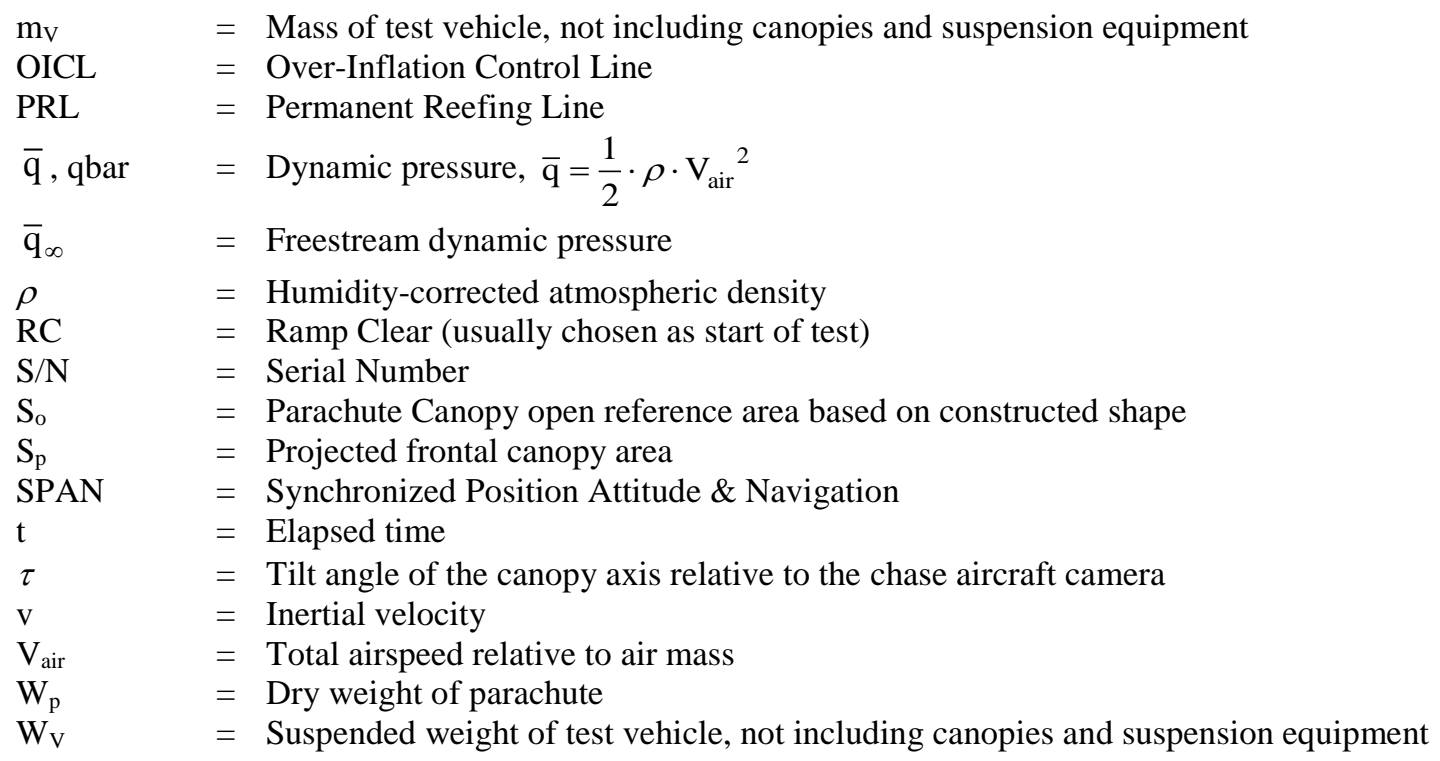

\section{Introduction}

MONG the largest components of the inflation loads of the Capsule Parachute Assembly System (CPAS) $116 \mathrm{ft}$

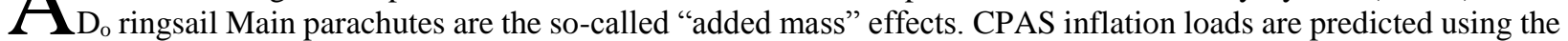
Flight Analysis and Simulation Tool (FAST), which is anchored by matching peak loads via flight test reconstructions. FAST reconstructions of the Main parachutes generally match the peak load magnitude, but the simulated peak load timing usually occurs much earlier than the actual data, especially during the disreef to full open. An example for Cluster Development Test (CDT)-3-7 is shown in Figure 1.

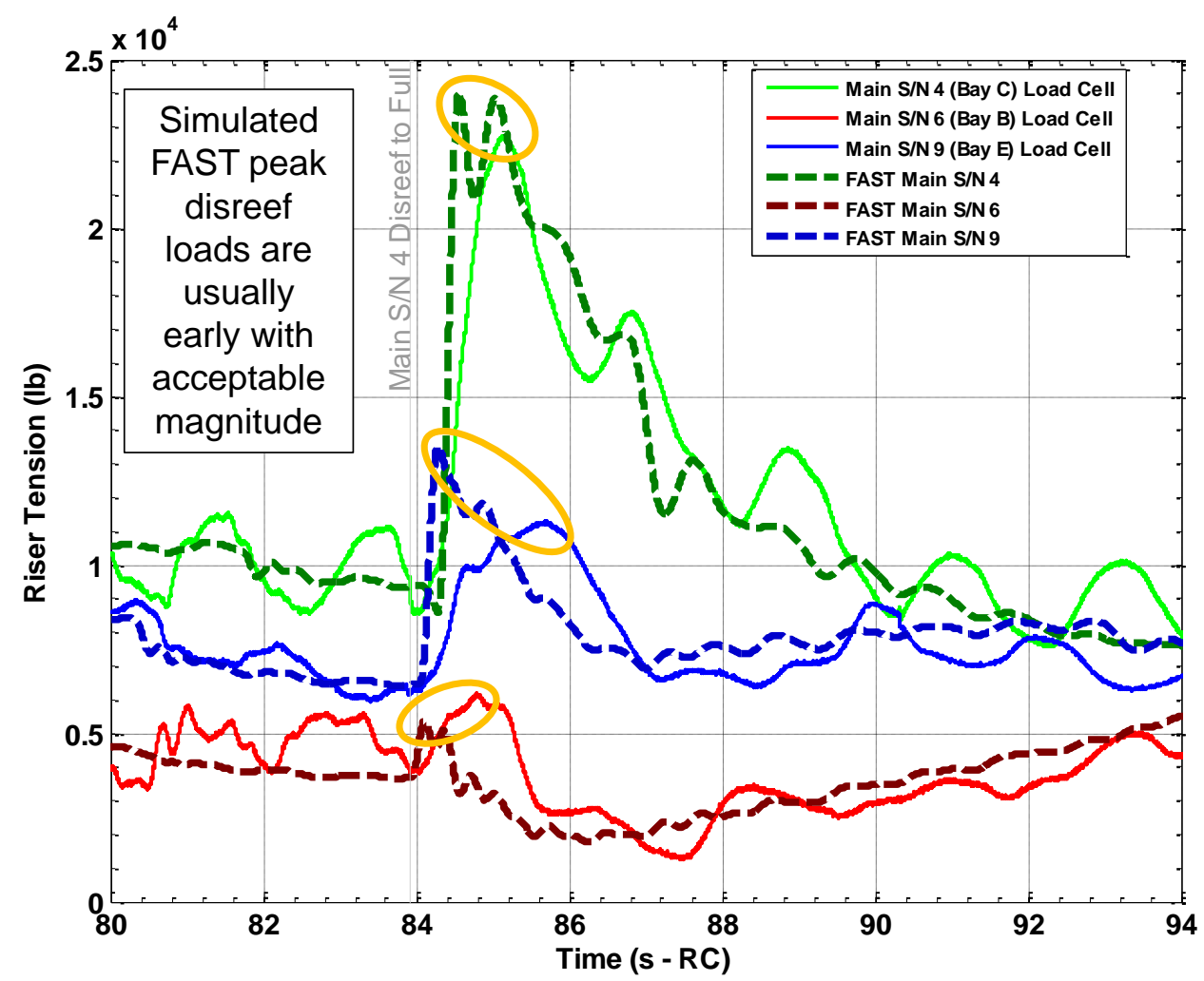

Figure 1. Typical FAST simulation (dashed lines) of disreef to full open with peak loads earlier than test data (solid lines).

American Institute of Aeronautics and Astronautics 
This discrepancy implies a lack of fidelity in the added mass model. Therefore, an effort was undertaken to better understand Main parachute added mass. Added mass can be divided into the "enclosed mass" of the air within each canopy plus the external "apparent mass" due to viscosity. The enclosed mass is the product of the enclosed air volume and ambient air density.

Fortunately, a wealth of CPAS Main deployment visual and digital information was available to estimate enclosed mass. On every flight starting with the Engineering Development Unit (EDU) test series, at least one chase helicopter was staged at an altitude to allow for nearly orthogonal side views of the inflating Main parachutes. The payloads incorporated upward-looking video cameras to observe the inflating shapes and cluster behavior. The avionics system on the payload provided highly accurate system state data, ${ }^{1}$ and the Main risers were instrumented for loads. ${ }^{2}$

This paper focuses on identifying the drag and momentum terms that make up the total inflation load to develop an alternate inflation model. This model leverages the high-quality data available to CPAS by re-parameterizing the system state in terms of enclosed volume. A companion paper $^{3}$ explains how still photos and video were used to estimate canopy time-varying volume by constructing 3-D models. An example of these models during the CDT-3-7 disreef to full open is shown in Figure 2.

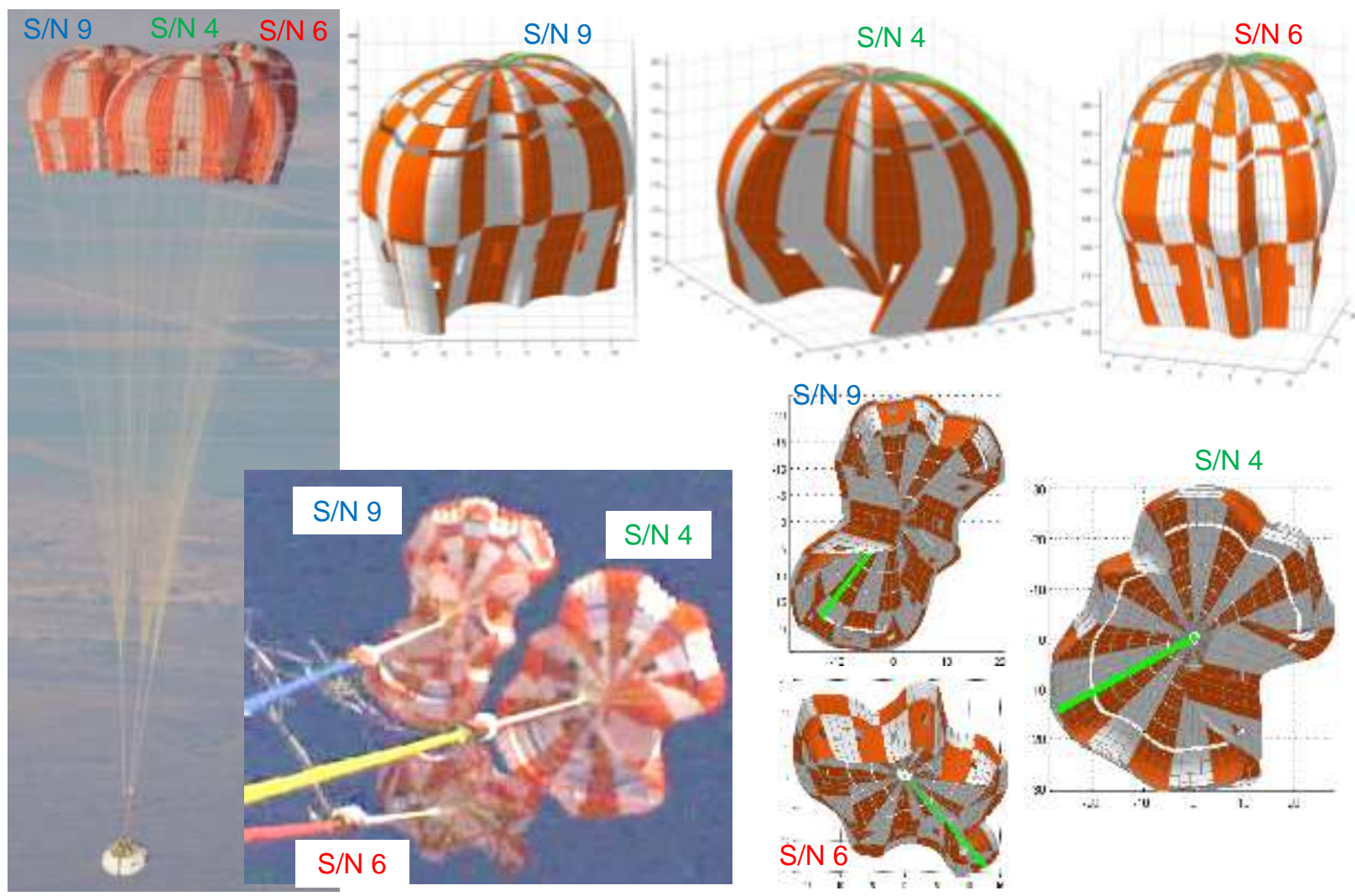

Figure 2. 3-D models of inflating canopies on CDT-3-7 compared to original chase helicopter photo and upward-looking HD video still.

Because calculating added mass requires knowledge of both the amount and rate of change of air mass in the canopy, it was important to have a series of photos taken in quick succession. Early in the test program, the photographers took fewer photographs during the Main parachute phase. The photographers were later encouraged to take photographs at a higher rate during key deployment and disreef events, especially as the cameras improved and their storage capacity expanded. A method was developed to synchronize chase photo timing, referenced to an absolute scale using the image metadata, and a comprehensive video timeline of known events (such as disreefs and touchdown) ${ }^{4}$ A summary of chase photo coverage and the status of volume analysis for Cluster Development Tests to date is presented in Table 1. The final three tests in the EDU series incorporated Over-Inflation Control Lines (OICL) or Permanent Reefing Lines (PRL) in an effort to control pendulum motion. Because the final design does not include such skirt restrictions, those tests are of lower priority for study. ${ }^{5}$ 
Table 1. Summary of CPAS Main Volume Analysis

\begin{tabular}{|c|c|c|c|c|c|}
\hline \multirow{2}{*}{ Test } & \multirow{2}{*}{ Vehicle } & \multicolumn{3}{|c|}{ Main Volume Analysis Status } & \multirow{2}{*}{ Notes } \\
\hline & & Bay B & Bay C & Bay E & \\
\hline CDT-2-2 & Weight Tub & \multicolumn{3}{|c|}{ Not enough photos } & Gen II with Added Porosity \\
\hline CDT-2-3 & Weight Tub & \multicolumn{3}{|c|}{ Not enough photos } & Gen II with Added Porosity \\
\hline CDT-3-1 & PCDTV & Not Visible & Sparse & Sparse & Upward-looking HD cameras failed \\
\hline CDT-3-2 & PCDTV & N/A & Complete & Complete & \\
\hline CDT-3-3 & PTV & Sparse & Not Visible & Sparse & Very few photos in $2^{\text {nd }}$ and full open \\
\hline CDT-3-4 & PCDTV & Skip $2^{\text {nd }}$ & Not Visible & Complete & Bay B skip $2^{\text {nd }}$ stage \\
\hline CDT-3-5 & PTV & Sparse & Sparse & Sparse & Bay B skip $1^{\text {st }}$ stage \\
\hline CDT-3-6 & PCDTV & Complete & Complete & Complete & No photogrammetry for validation \\
\hline CDT-3-7 & PTV & Complete & Complete & Complete & Bay B obscured during full open \\
\hline CDT-3-8 & PCDTV & Flagging mod. & Complete & Complete & Sparse early; Chase helo above Mains \\
\hline CDT-3-9 & PTV & Skip $1^{\text {st }}$ & Complete & Complete & Bay E obscured in $1^{\text {st }}$ stage \\
\hline CDT-3-11 & PTV & Skip, cut & Sparse & Sparse & Bay B not visible; Gaps between stages \\
\hline CDT-3-10 & PTV & Complete & Complete & Complete & Bay C obscured during full open \\
\hline CDT-3-12 & PCDTV & N/A & Complete & Complete & \\
\hline EFT-1 & Orion CM & \multicolumn{3}{|c|}{ Insufficient Coverage } & \\
\hline CDT-3-13 & PTV & Complete & Complete & Complete & Bay B obscured in $1^{\text {st }}$ stage \\
\hline CDT-3-14 & PTV & Skip $2^{\text {nd }}$ & Complete & Complete & Bay B skip $2^{\text {nd }}$ stage; Chase above \\
\hline CDT-3-15 & PTV & N/A & Complete & Complete & OICL and shorter riser \\
\hline CDT-3-16 & PTV & Pending & N/A & Pending & Sparse coverage in early stages; PRL \\
\hline CDT-3-17 & PCDTV & Pending & Pending & Pending & PRL \\
\hline
\end{tabular}

Certain features of the 3-D models were validated with previous photogrammetric analysis performed by the JSCKX Image Science \& Analysis Group using upward-looking High Definition (HD) videos. That analysis used automated tracking to characterize individual canopy skirt perimeter, maximum projected area $\left(S_{\mathrm{p}}\right)$, and cluster flyout angle $(\theta) .{ }^{6,7}$

A previous study of a single Main inflation was conducted by Airborne Systems using a ground-based camera to estimate the canopy volume by approximating an ellipsoid shape. ${ }^{8}$ That study indicated that the added mass effects were negligible in the first stage, were more significant in the second stage, and were most significant during the disreef to full open, which also matches the current observations. Since the Airborne study, the CPAS Main canopy geometry has since changed with the addition of a ring gap and removal of several panels to improve cluster performance. ${ }^{9}$ The current effort also differs from that study by characterizing cluster effects, which often cause the canopies to take irregular shapes due to mutual aerodynamic interference.

The equations for added mass and the simulation methodology is discussed in Section II. Selected flight test results are presented in Section III.

\section{Added Mass Equations Using Volume Method}

The current parachute inflation models used by NASA can trace their heritage to a 6-DOF code used by the Viking program called UD233. ${ }^{10}$ The inflation model, including the added mass algorithm, was later utilized by the Decelerator System Simulation (DSS). ${ }^{11}$ During the CPAS program, DSS was modified to better align with the DCLDYN (Decelerator Dynamics) simulation, then used by Airborne Systems. ${ }^{12}$ The DSS inflation parameters were modified to allow for common inputs anchored to flight test reconstructions. An added mass filter was added to DSS which emulated DCLDYN, but did not incorporate any of its code directly. Unfortunately, there are significant gaps in the known heritage of the legacy added mass model. An examination of the DSS source code implies that the algorithm was changed over time to match data from available test programs, using geometric approximations and undocumented scale factors. When CPAS transitioned to FAST, the algorithms were migrated essentially unchanged.

The history of added mass has been presented by many authors over the years. Much of this history was recently summarized in Ref. 13. The equations for all inflating parachutes are derived from Newton's second law of motion, the general form of which is given in Eq. (1). A simplified free body diagram of a decelerating parachute system is 
shown in Figure 3. It is assumed that the parachute deceleration vector, the freestream air $\left(\mathrm{V}_{\text {air }}\right)$ and inertial velocity (v) vectors are co-aligned. The elastic spring force is neglected in this study but is included in FAST.

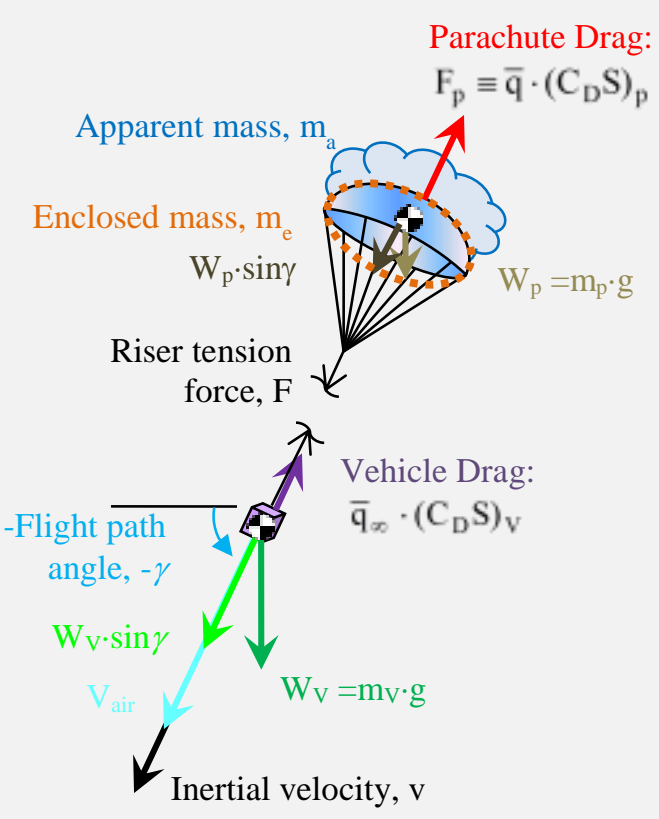

Figure 3. Deceleration with added mass (neglecting spring force).

$$
\sum \mathrm{F}=\frac{\mathrm{d}}{\mathrm{dt}} \sum(\mathrm{m} \cdot \mathrm{v})
$$

The rate of change of momentum can be written in terms of variable mass multiplied by the system velocity, and fixed masses multiplied by accelerations. The relevant terms from the free body diagram of the isolated parachute are listed in Eq. (2).

$$
\mathrm{F}+\mathrm{W}_{\mathrm{p}} \sin (-\gamma)-\operatorname{Drag}=\frac{\mathrm{d}}{\mathrm{dt}}(\mathrm{m}) \cdot \mathrm{v}+\frac{\mathrm{d}}{\mathrm{dt}}(\mathrm{v}) \cdot \mathrm{m}
$$

The items are expanded and re-arranged to yield the components of riser tension $(\mathrm{F})$ in Eq. (3). Added mass $\left(\mathrm{m}_{\mathrm{A}}\right)$ is defined in this formulation as the sum of the enclosed air mass $\left(m_{e}\right)$ and apparent mass $\left(m_{a}\right)$. The dry mass of the parachute $\left(\mathrm{m}_{\mathrm{p}}\right)$ is multiplied by gravity $(g)$ to produce the weight of the parachute $\left(\mathrm{W}_{\mathrm{p}}\right)$. The CPAS Main canopy weight is currently about 250 pounds, including suspension equipment, so the dry mass terms are much smaller than the other inflation forces.

$$
\mathrm{F}=\mathrm{C}_{\mathrm{D}} \mathrm{S} \cdot \overline{\mathrm{q}}+\frac{\mathrm{d}\left(\mathrm{m}_{\mathrm{e}}+\mathrm{m}_{\mathrm{a}}\right)}{\mathrm{dt}} \cdot \mathrm{v}+\left(\mathrm{m}_{\mathrm{e}}+\mathrm{m}_{\mathrm{a}}+\mathrm{m}_{\mathrm{p}}\right) \cdot \frac{\mathrm{d}(\mathrm{v})}{\mathrm{dt}}+\mathrm{W}_{\mathrm{p}} \sin \gamma
$$

A generic block diagram of a typical algorithm that computes riser tension from inflation loads, used by simulations such as DSS or FAST, is shown in Figure 4. Inflation parameters such as fill distance constant, exponential shape term, and drag area are reconstructed from flight tests. These parameters are inputs to the algorithm and are often dispersed, as in Ref. 14. They describe parachute drag area growth with time. Simulations used by CPAS assume that drag area monotonically increases with time, although data often show drag reduction in "lagger" canopies due to cluster interference. Drag area growth is then related to the growth of canopy volume through some sort of geometrical assumption. Drag area is multiplied by dynamic pressure to produce a drag force. The growing air mass in the canopy is used to estimate added mass and added mass rate terms, which are then combined with the other forces to produce the total parachute riser tension.

American Institute of Aeronautics and Astronautics 


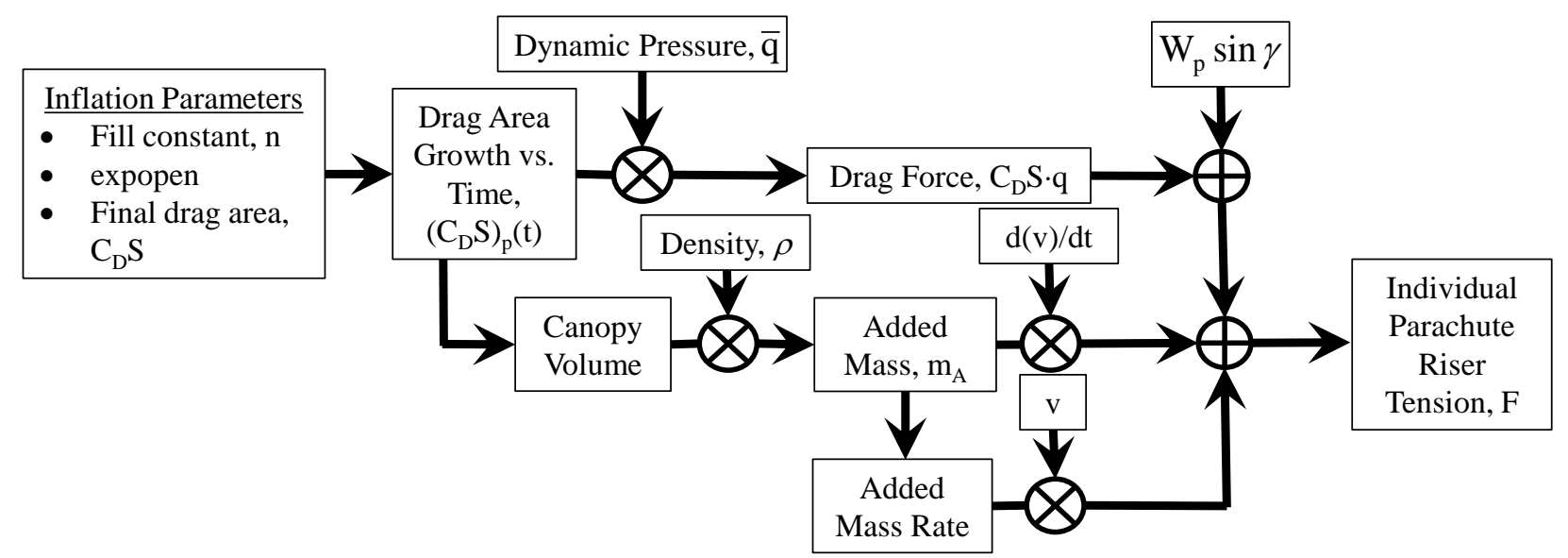

Figure 4. Typical algorithm for simulating riser tension (e.g. DSS and FAST).

The formulation of the proposed algorithm, shown in Figure 5, differs in that the enclosed volume state, rather than the drag area, is the primary independent variable that is matched to time varying flight test data. The examples in this study fit volume data with third order polynomials, which can allow brief volume reduction in a cluster. The canopy volume is used to compute drag area using a look-up table that is also derived from flight test data. The canopy volume and drag area states are then used to compute riser tension similarly to the typical algorithm.

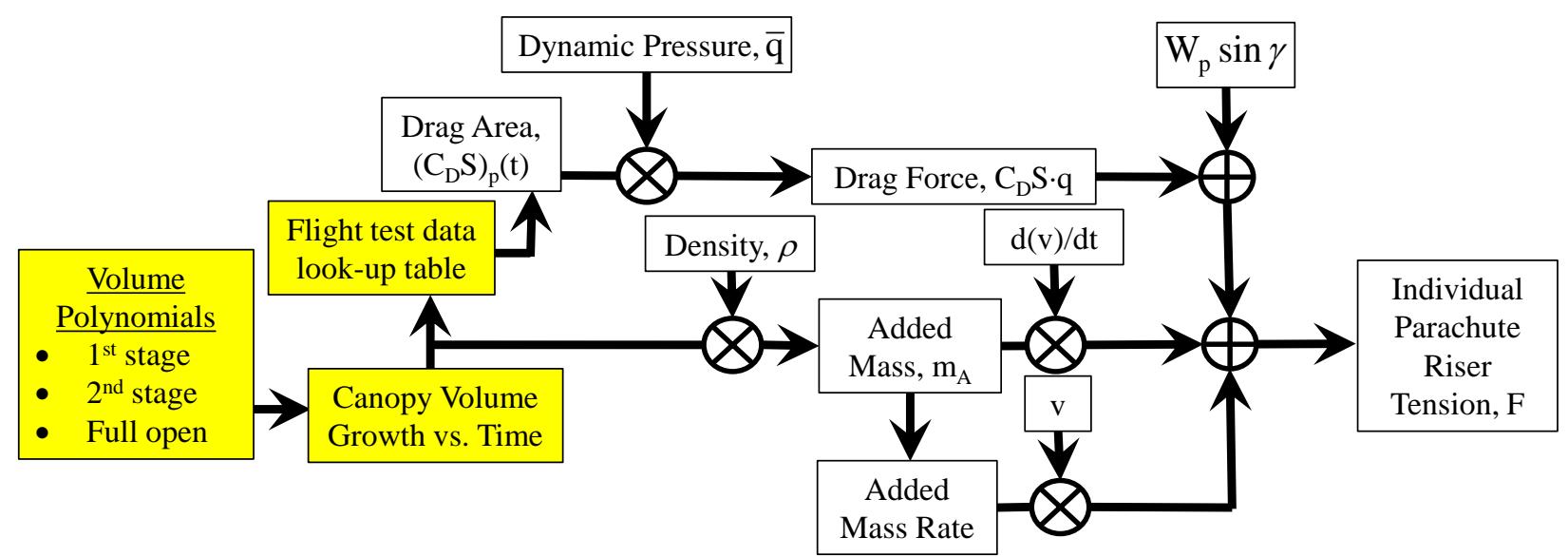

Figure 5. Alternative riser tension algorithm (volume method) with differences highlighted.

The rate of change of velocity at the vehicle, $\mathrm{d}(\mathrm{v}) / \mathrm{dt}$, can be calculated using three different methods. Note that this term should not include the gravity acceleration vector (typically measured in most accelerometers), because it is assumed that enclosed air is neutrally buoyant. CPAS currently instruments its test vehicles with the NovAtel SPANSE (Synchronized Position Attitude \& Navigation), ${ }^{15}$ which combines GPS readings with an accelerometer housed in an IMU ${ }^{16}$ into an integrated state solution via a Kalman filter. The first method is to directly obtain the inertial change of velocity as output from the post processing software, Inertial Explorer. ${ }^{17}$ This output was confirmed with two independent alternate methods, which may be used if the direct output is not available. One method is to numerically differentiate the velocity state in all three directions. The other is to transform the raw acceleration readings from the body axis to an inertial frame using Euler angles, and then remove the gravity term from the vertical direction.

Construction of the drag area look-up table for the proposed volume method involves isolating drag from the flight test data through process of elimination. Two other methods were considered but were ultimately discarded. One option would be to compute drag through Computation Fluid Dynamics (CFD). The "Bi-model" of Potvin and McQuilling computes canopy drag using a series of static CFD solutions for slowly-inflating canopies. ${ }^{18}$ The Bi-model is so named because it is part-way between traditional low-fidelity modeling and Fluid Structure Interaction (FSI). Although initially considered for this current study, the Bi-model takes advantage of geometrical assumptions, such as radial symmetry and pressurized shape that are not well suited for the clusters of CPAS Mains, which deform due

American Institute of Aeronautics and Astronautics 
to cluster effects. The other option would be to model the parachutes with FSI. The Team for Advanced Flow Simulation and Modeling ${ }^{19}$ at Rice University, led by Prof. Tayfun Tezduyar, has been successful in modeling many features of CPAS-like ringsail parachutes using FSI. These include cluster effects ${ }^{20}$ and reefed stages. ${ }^{21}$ However, the high computational cost for FSI was prohibitive for this study.

While computing enclosed mass is fairly straightforward using canopy volume and density data, apparent mass is much more difficult to quantify. Potential flow theory provided apparent mass formulations for certain shapes such as spheres and ellipsoids. Heinrich used wind tunnel test data and geometric assumptions to postulate that a linearlygrowing apparent mass term would eventually be equal to $3 / 8$ of enclosed mass by full open, as quoted in Ref. 22 . He and Noreen noted that even if apparent mass was initially small, the time derivative could be significant. ${ }^{23}$ Experiments by Yavuz and Cockrell indicated that the apparent mass coefficient is more significant than potential flow theory would suggest, and varies with angle of attack and an acceleration modulus. ${ }^{24}$

Because this study carefully tracks the growth of enclosed mass, it was assumed that apparent mass could be directly related to enclosed mass via a scale factor, $\mathrm{K}_{\mathrm{ae}}$. However, initial reconstructions showed an acceptable match of peak inflation loads by setting this scale factor to zero. It is likely that any actual apparent mass is therefore being erroneously accounted for in either the drag area or enclosed mass terms. Better identifying drag area through CFD might reduce this uncertainty. The actual apparent mass formulation may eventually be determined by simultaneously optimizing the reconstructions of several tests over a wide range of test conditions. The reconstructions presented below initially assume $\mathrm{K}_{\mathrm{ae}}$ is zero, and each conclude with a sensitivity analysis.

\section{Selected Flight Data Results}

Test analysis begins by validating geometrical inputs to gain confidence in the volume data. During reefed stages, the maximum perimeter of the skirt is constrained to be no larger than the length of the reefing line, $\mathrm{L}_{\mathrm{r}}$. Each of the flights examined here had full open skirt perimeter and projected area photogrammetric data analysis performed by the KX Image Science \& Analysis Group. As will be shown, these data provide a useful proxy for volume when chase photos are scarce. The inflation load components are built up term by term and compared to the measured total riser tension.

A simulation for each canopy is performed at each analysis step. However, rather than constructing a stand-alone 3-DOF or 6-DOF simulation, the current simulation merely assumes a perfect match of the state by interpolating the known Best Estimate Trajectory (BET) data with time. Eventually, the volume method may be incorporated into FAST as an alternative inflation model.

\section{A. CDT-3-2}

The second EDU test, CDT-3-2, descended under two Mains. 3-D surfaces were generated for both canopies and are compared to the original images for all three stages in Figure 6.

American Institute of Aeronautics and Astronautics 

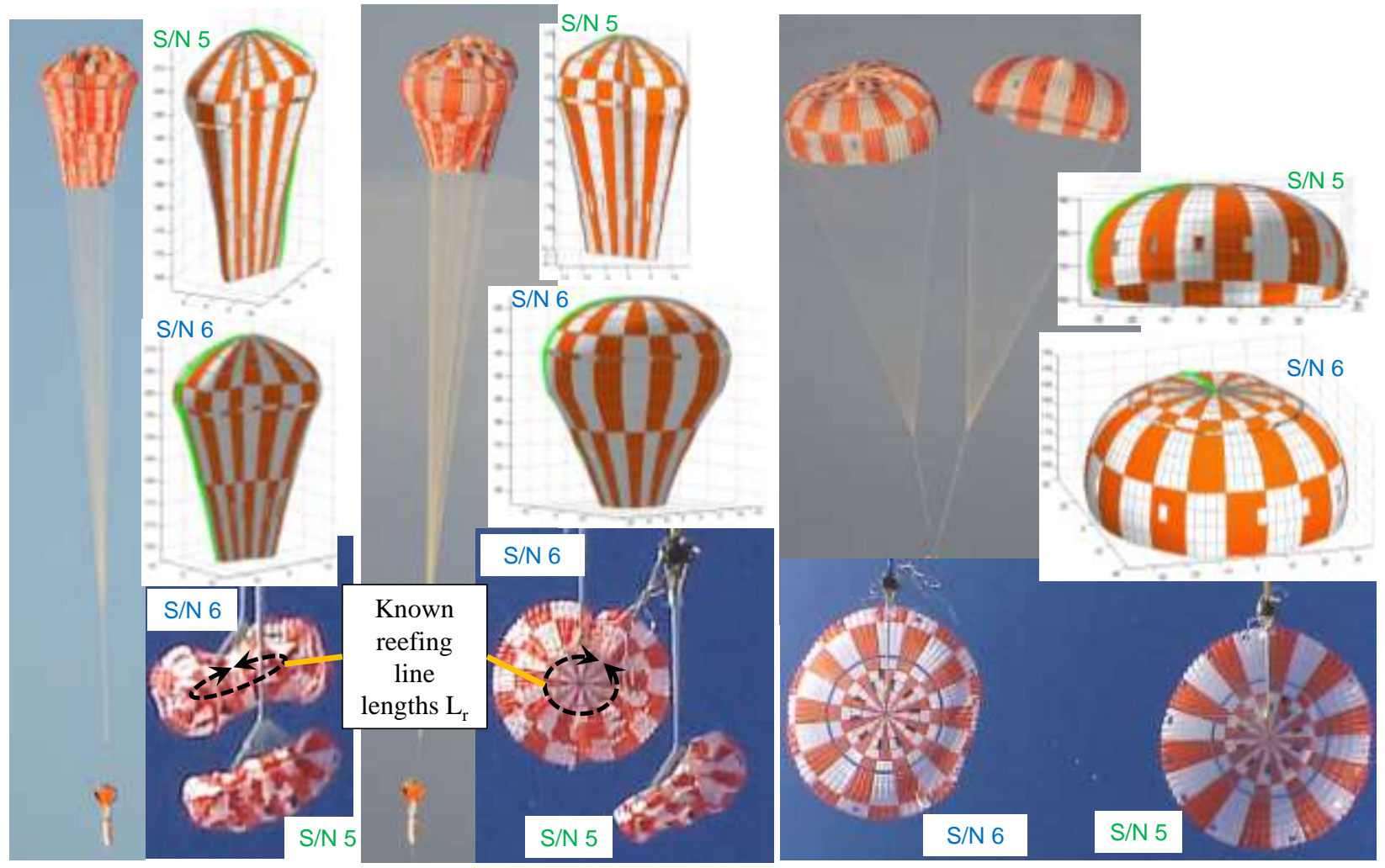

Figure 6. CDT-3-2 selected 3-D canopy models at all three inflation stages.

The estimated skirt perimeter matches up with the reefing line lengths and KX analysis in Figure 7.

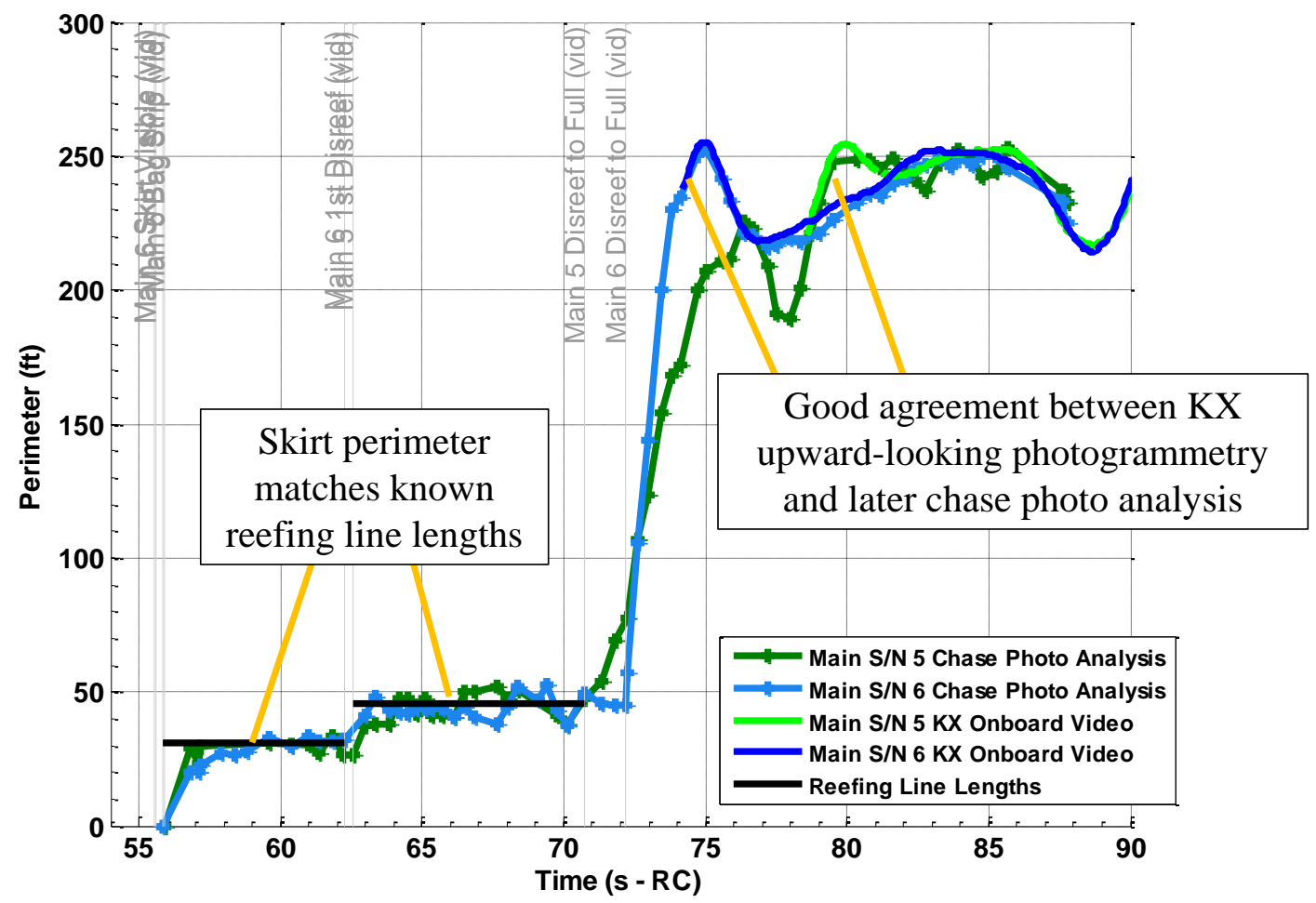

Figure 7. CDT-3-2 skirt perimeter validation.

American Institute of Aeronautics and Astronautics 
This agreement should instill confidence in the computed enclosed volume data plotted in Figure 8.

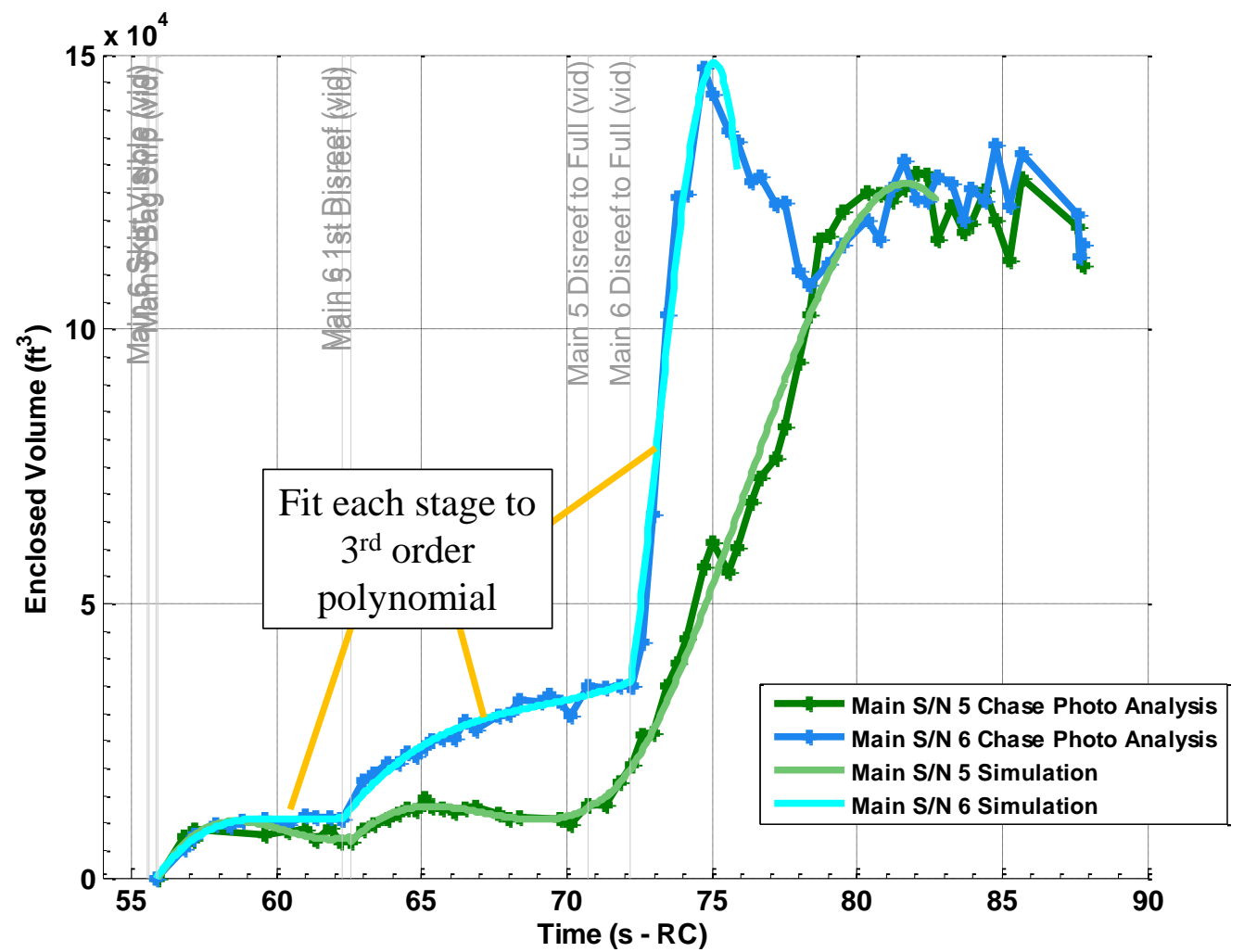

Figure 8. CDT-3-2 enclosed volume data and polynomial curve fits.

The enclosed volume for each canopy was fit with a third order polynomial for each stage. Main S/N 5 shows some reduction in volume at the end of first and second stages. This is consistent with the photos which show that Main S/N 6 is the dominant canopy, reducing the airflow into its neighbor. The last data to be fit were immediately after inflation, when each canopy finished over-expanding. This feature differs from the current CPAS inflation assumptions where each canopy inflates directly to its average full open drag area with no oscillation. The final oscillation may be suited to hand off to the CPAS time varying rate of descent model. ${ }^{25}$

It was observed that the enclosed volume makes a linear trend with projected area, as shown in Figure 9. This was an unexpected result based on the canopy geometric assumptions made by most inflation codes. For example, the volume of a hemisphere is proportional to projected area to the $3 / 2$ power. The shape for a conical frustum/hemisphere model (such as that used by Heinrich) would make an S-curve. The slope for each linear fit is shown in the legend.

American Institute of Aeronautics and Astronautics 


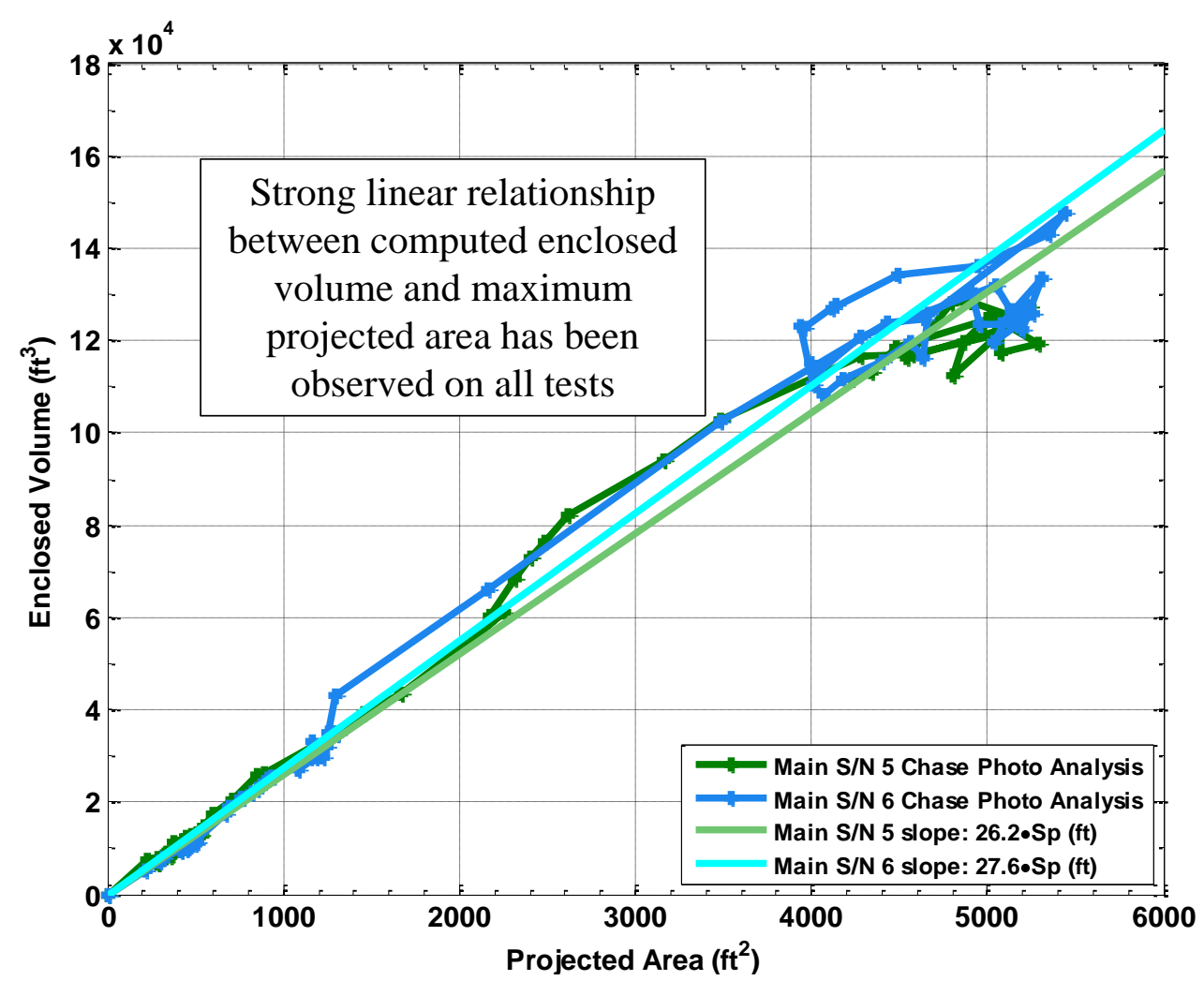

Figure 9. CDT-3-2 linear fit of enclosed volume vs. projected area.

The assumption of a direct relationship between enclosed volume and projected area allowed for the transformation of the volume polynomial curves to projected area curves, which are compared with the original data in Figure 10.

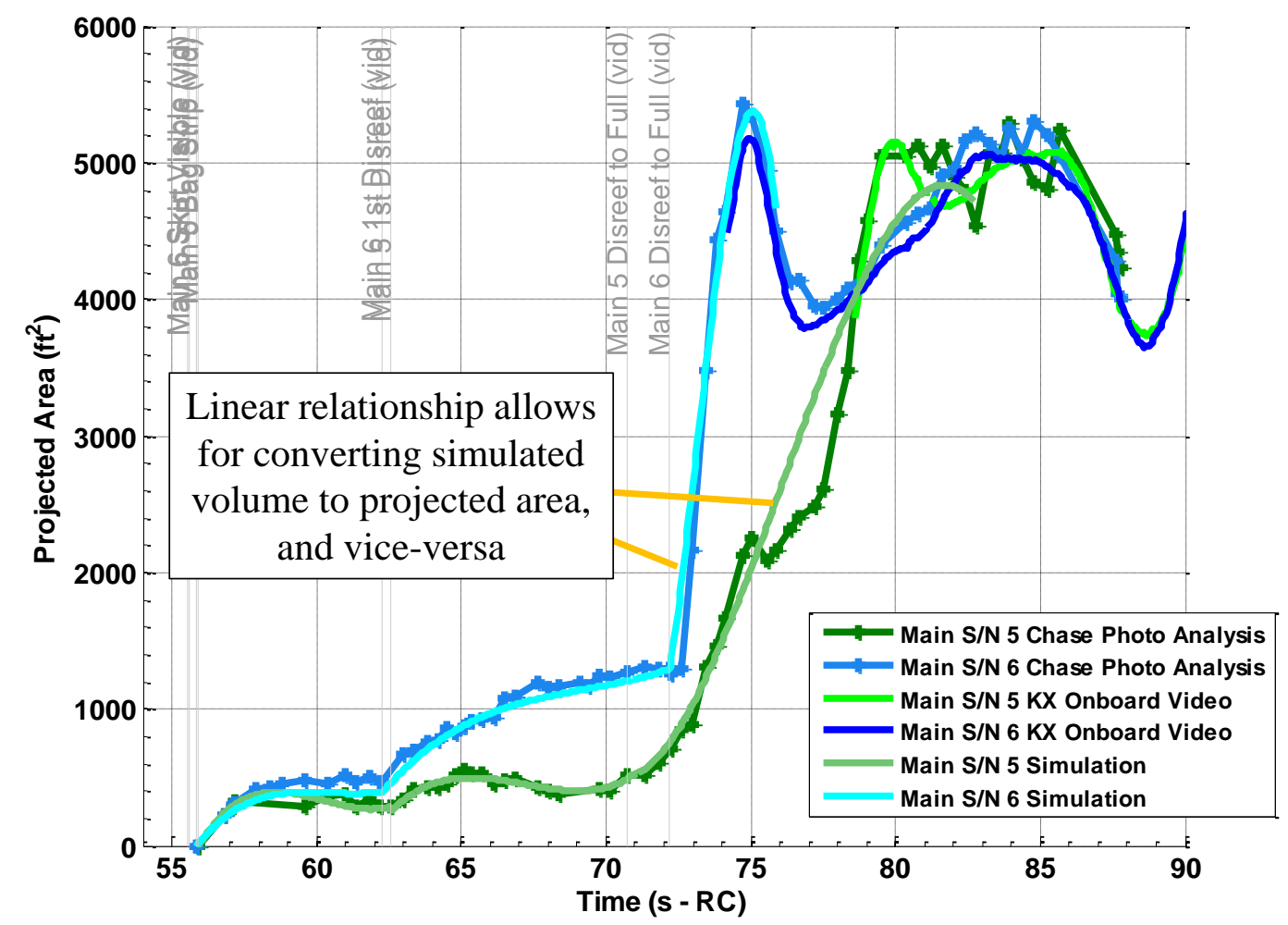

Figure 10. CDT-3-2 projected area.

American Institute of Aeronautics and Astronautics 
The original volume data were numerically differentiated to compute enclosed volume rate through finite differencing. Results are plotted in Figure 11. This process is always susceptible to error when there is noise in the data. The simulation differentiated each third order volume polynomial, so the results are smoother. Due to the approximate nature of the volume curve fits, the simulated volume rates do not match the peaks in the data. This is acceptable because those peaks may be exaggerated from the numerical differentiation. Any negative volume rate was set to zero, so as to ensure each canopy contributes to system deceleration but not acceleration.

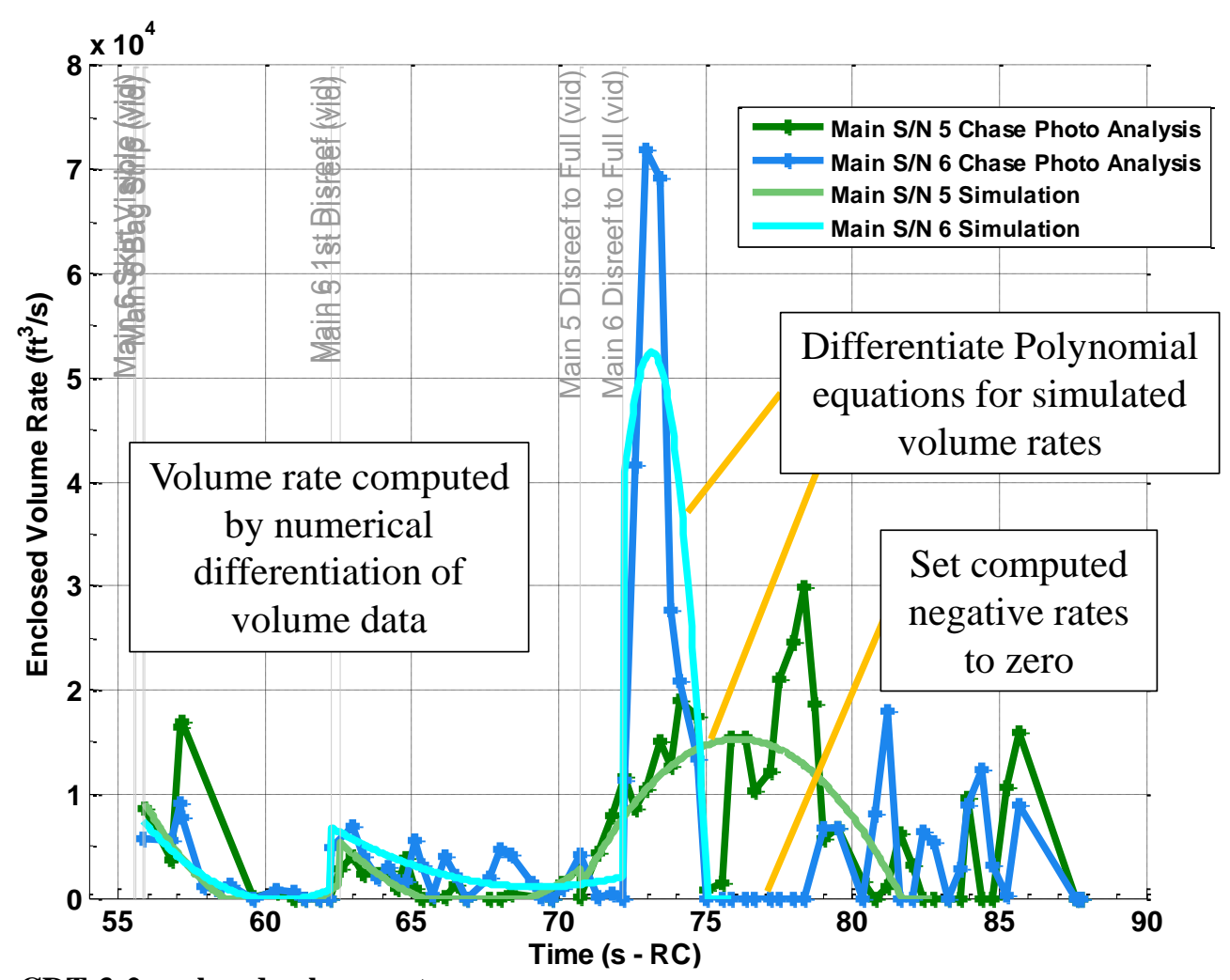

Figure 11. CDT-3-2 enclosed volume rate.

The enclosed mass was computed by multiplying enclosed volume by ambient atmospheric density from the day of flight Best Estimate Atmosphere (BEA). Density was stored as a function of altitude, which is interpolated from the vehicle state data. The enclosed air mass is shown in Figure 12 and the enclosed air mass rate is shown in Figure 13.

American Institute of Aeronautics and Astronautics 


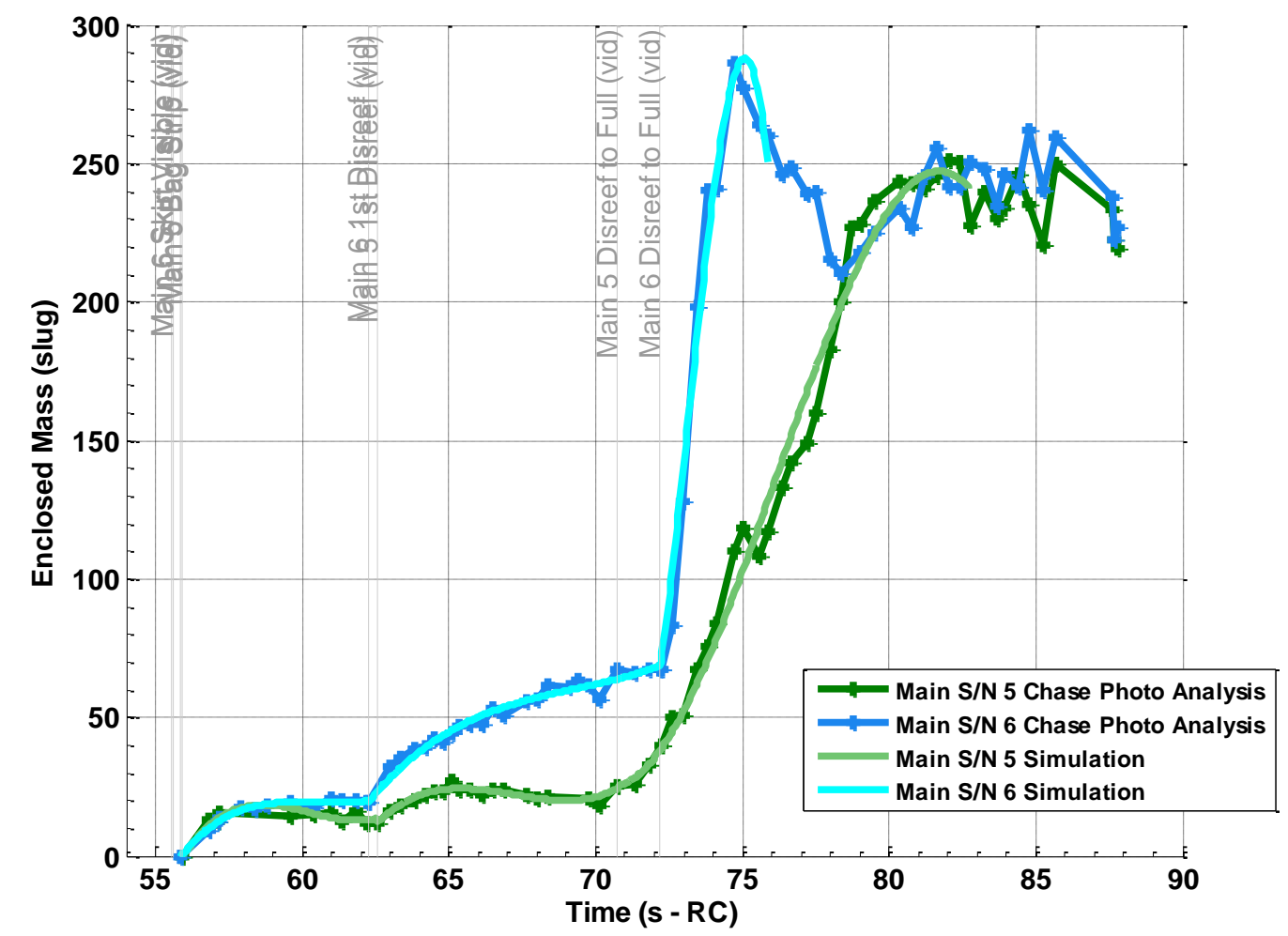

Figure 12. CDT-3-2 enclosed mass.

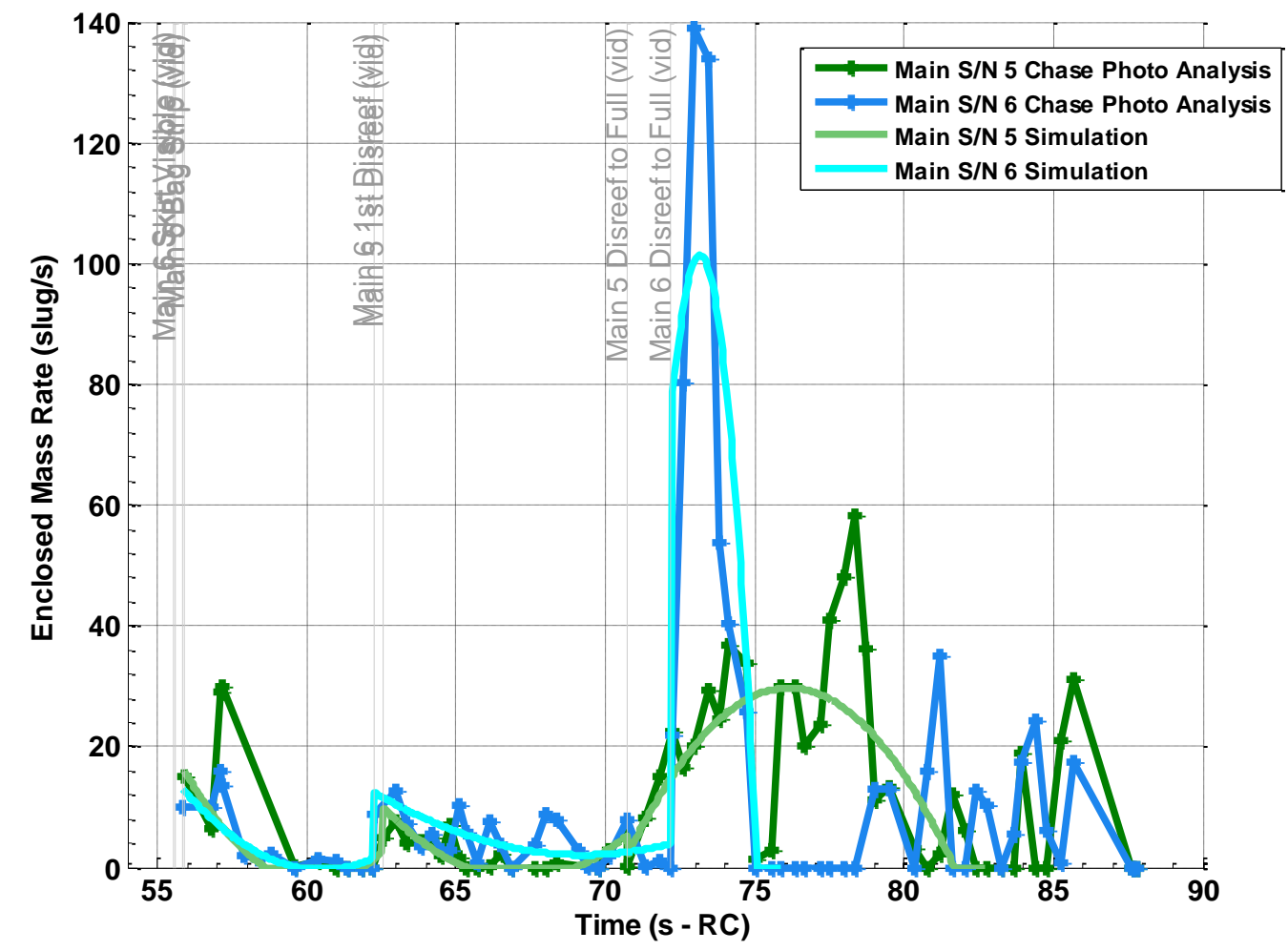

Figure 13. CDT-3-2 enclosed mass rate. 
The enclosed mass rate is then multiplied by the vehicle velocity (interpolated from the SPAN-SE state data) to compute the added mass rate-based term, plotted in Figure 14. As mentioned previously, although the code carries the apparent mass parameter $\left(\mathrm{m}_{\mathrm{a}}\right)$, it is currently assumed to be zero.

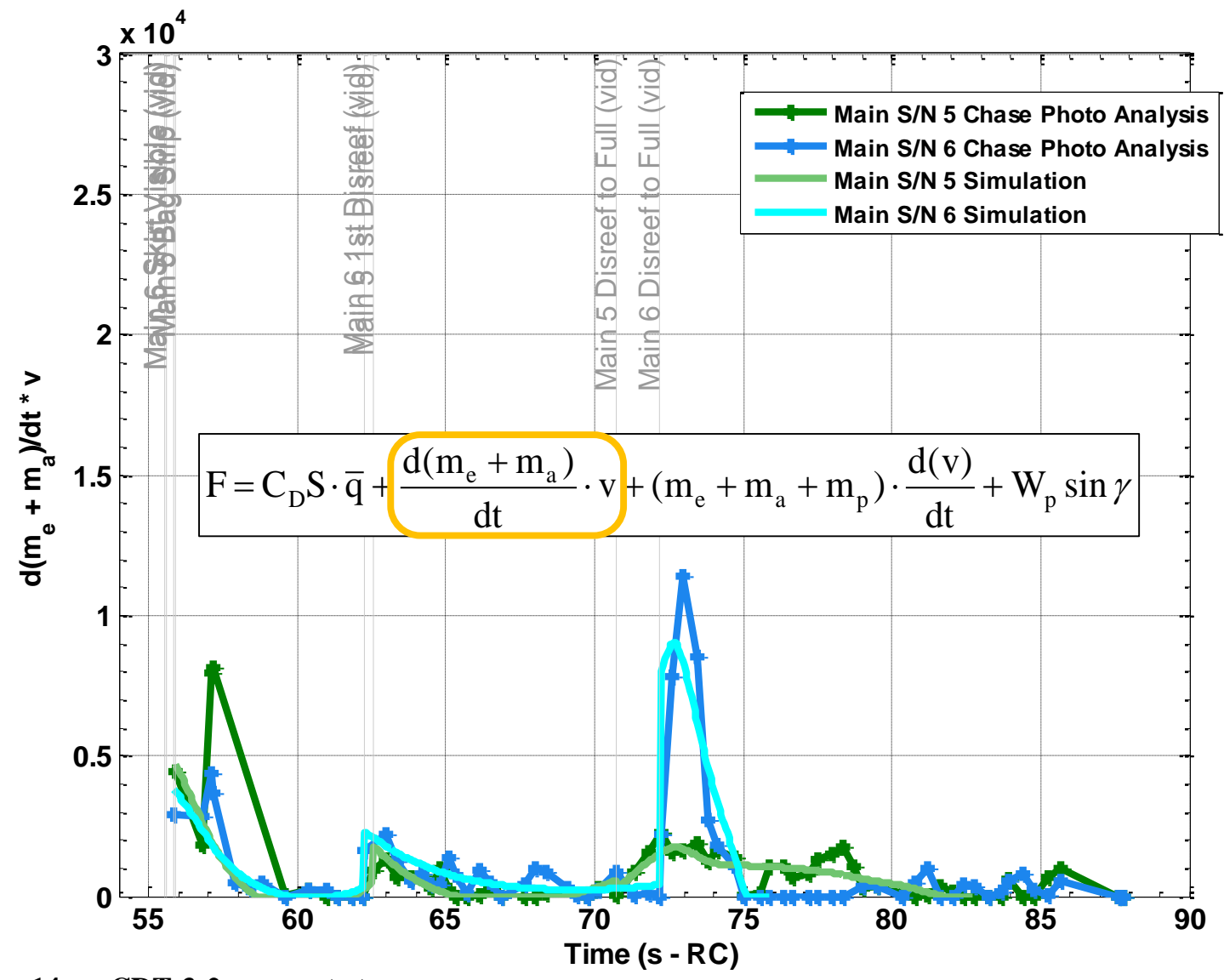

Figure 14. CDT-3-2 mass rate term. 
The mass values are multiplied by the derivative of inertial velocity (interpolated from the SPAN-SE state data) to compute the added mass velocity rate term, which is plotted in Figure 15.

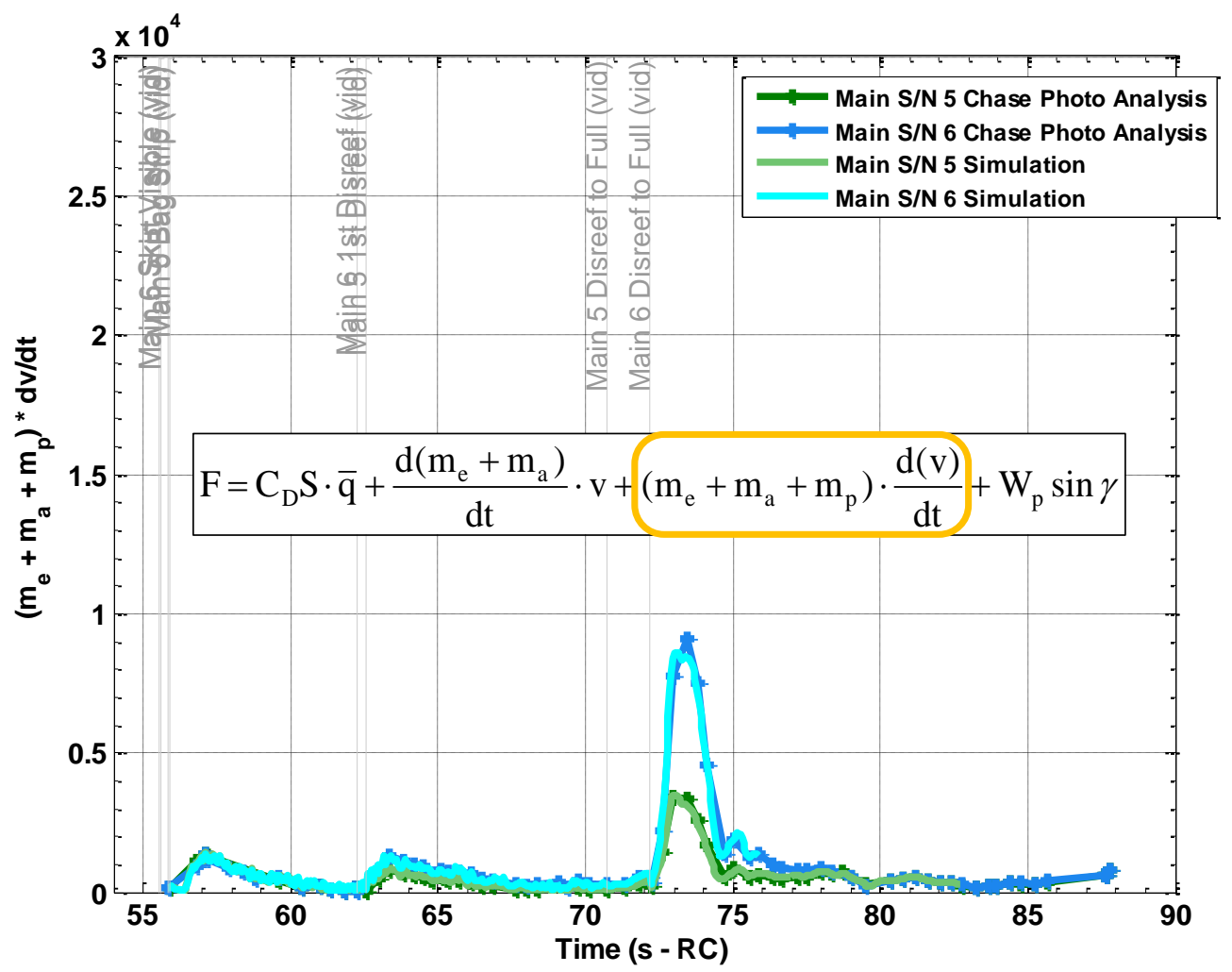

Figure 15. CDT-3-2 velocity rate term. 
Finally, the parachute dry mass term is shown in Figure 16. As expected, this term is of much lower significance than the added mass terms.

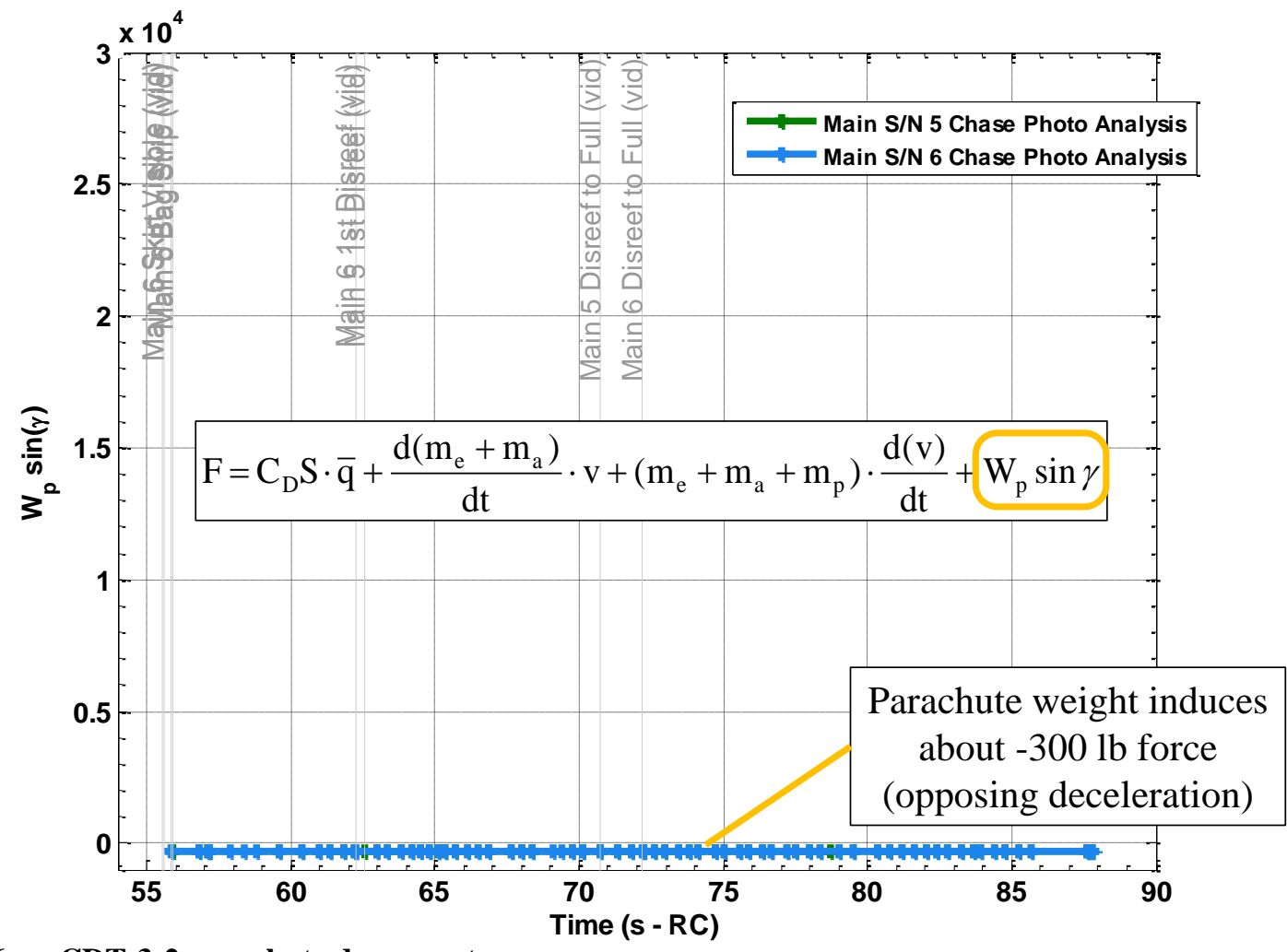

Figure 16. CDT-3-2 parachute dry mass term. 
The load terms (other than drag) are added together and compared with the measured riser loads in Figure 17. The peak measured tensions are coincident in time with the peak added mass loads. The added mass peak magnitudes grow in significance with each stage, indicating the importance of modeling added mass for these canopies. As expected, the computed loads do not exceed the total riser tension at any point. Therefore, the difference between riser tension and these other loads must be due to drag area growth (neglecting spring elongation and apparent mass).

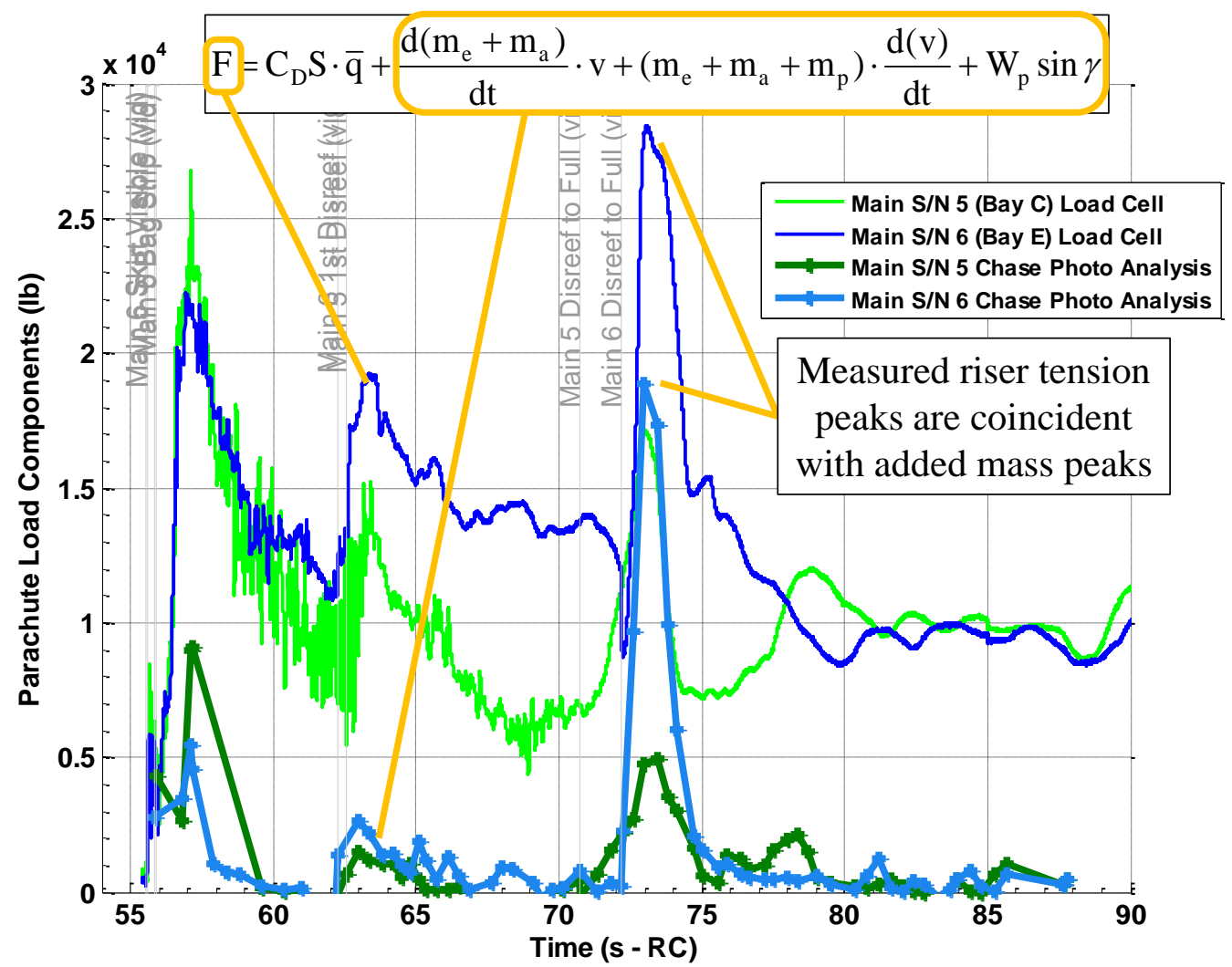

Figure 17. CDT-3-2 parachute load components compared with riser tension. 
The isolated drag area for each canopy is plotted against enclosed volume in Figure 18. This information is used to determine key empirical look-up tables for each flight. The overall trend could be described as quadratic. Therefore, the data are fit for each stage with second order polynomials for simplicity. The first and second stages (inset) show concave-down trends. This is most likely due to the cluster interference effects at the end of the reefed stages. The large differences between curves for both canopies are most likely due to aerodynamic and surface shape differences. Full open data are only fit through the end times of the curve fit plots shown previously. Therefore, no attempt is made to match the full open data in the upper right which oscillates about a volume of $120,000 \mathrm{ft}^{3}$ and drag area of $10,000 \mathrm{ft}^{2}$.

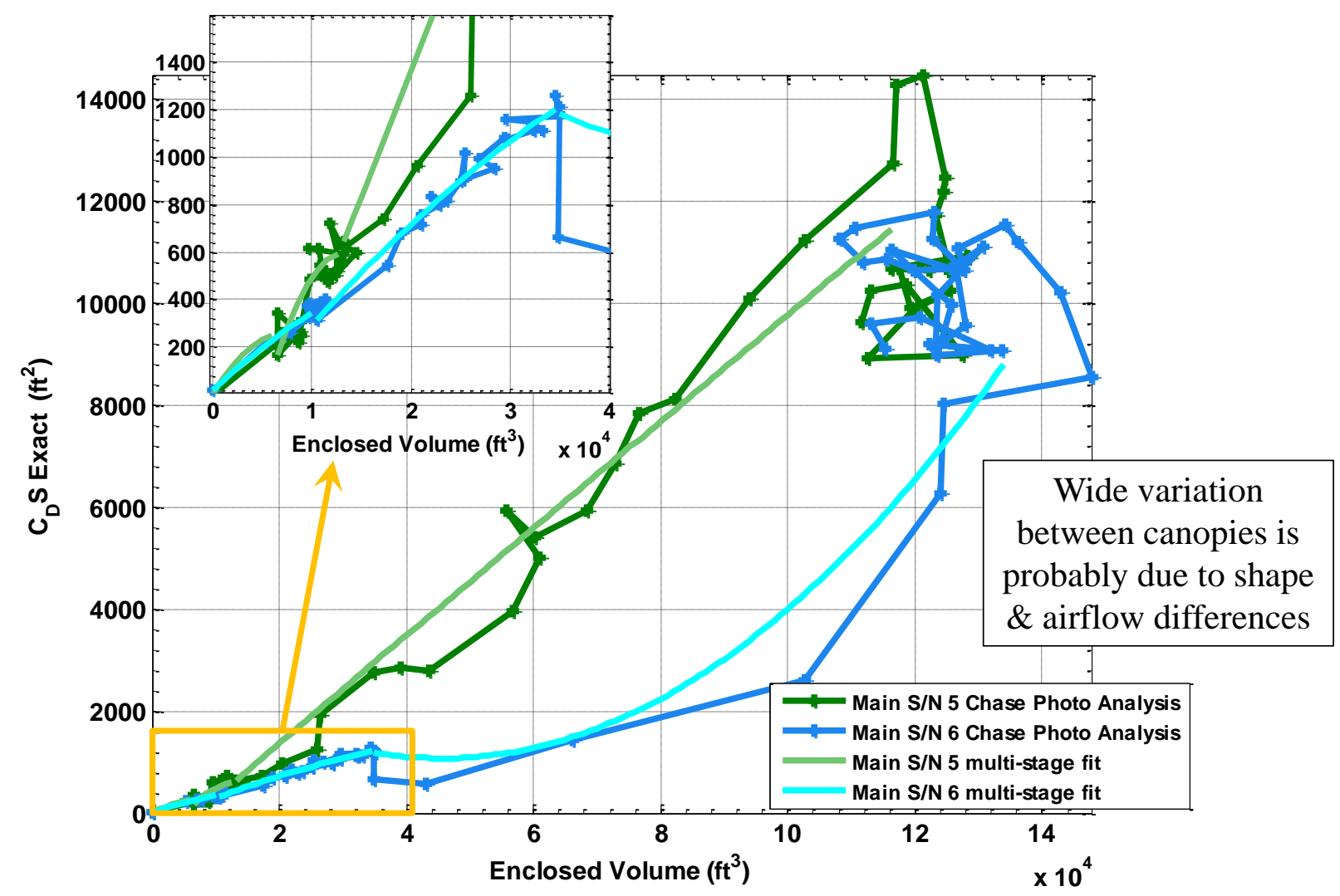

Figure 18. CDT-3-2 isolated drag area vs. enclosed volume.

American Institute of Aeronautics and Astronautics 
The curve fits are then used to compute the drag area growth with time. The drag area is multiplied by interpolated dynamic pressure to compute the isolated canopy drag forces, plotted in Figure 19. Each stage shows a sudden dropoff in drag just after each disreef. This is most likely due to the sudden loss of pressure applied to the lower end of the canopy as the skirt suddenly expands. This sudden drop-off in load has been observed for some time, but has not been modeled in any CPAS simulation until now.

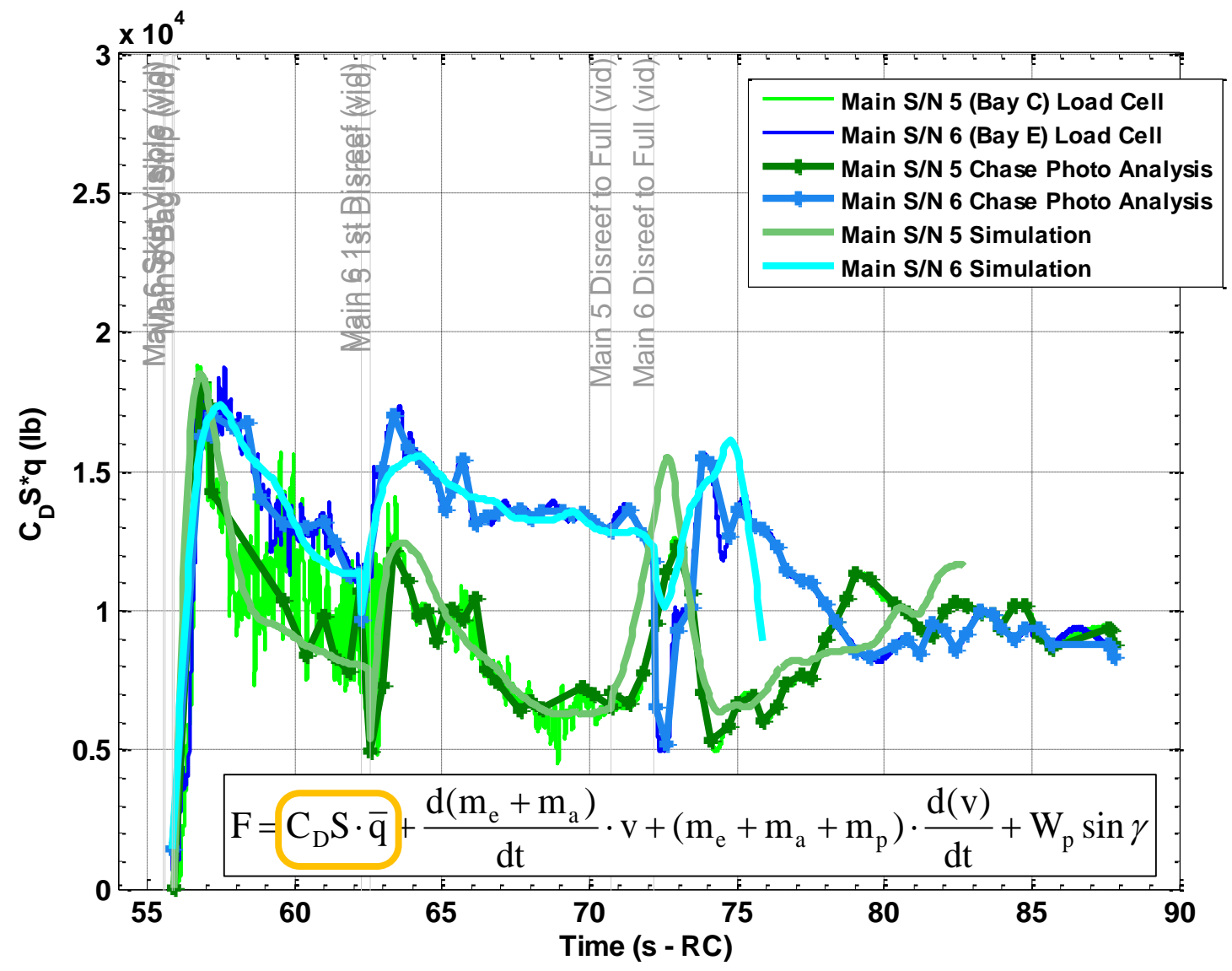

Figure 19. CDT-3-2 isolated drag force. 
The curve fits are then used to compute the drag area growth with time. The results are plotted in Figure 20. For this case, the volume method succeeds in matching the observed peak riser tension timing and magnitude, especially in the disreef to full open. FAST simulations of disreef peak loads generally match the magnitude but occur earlier.

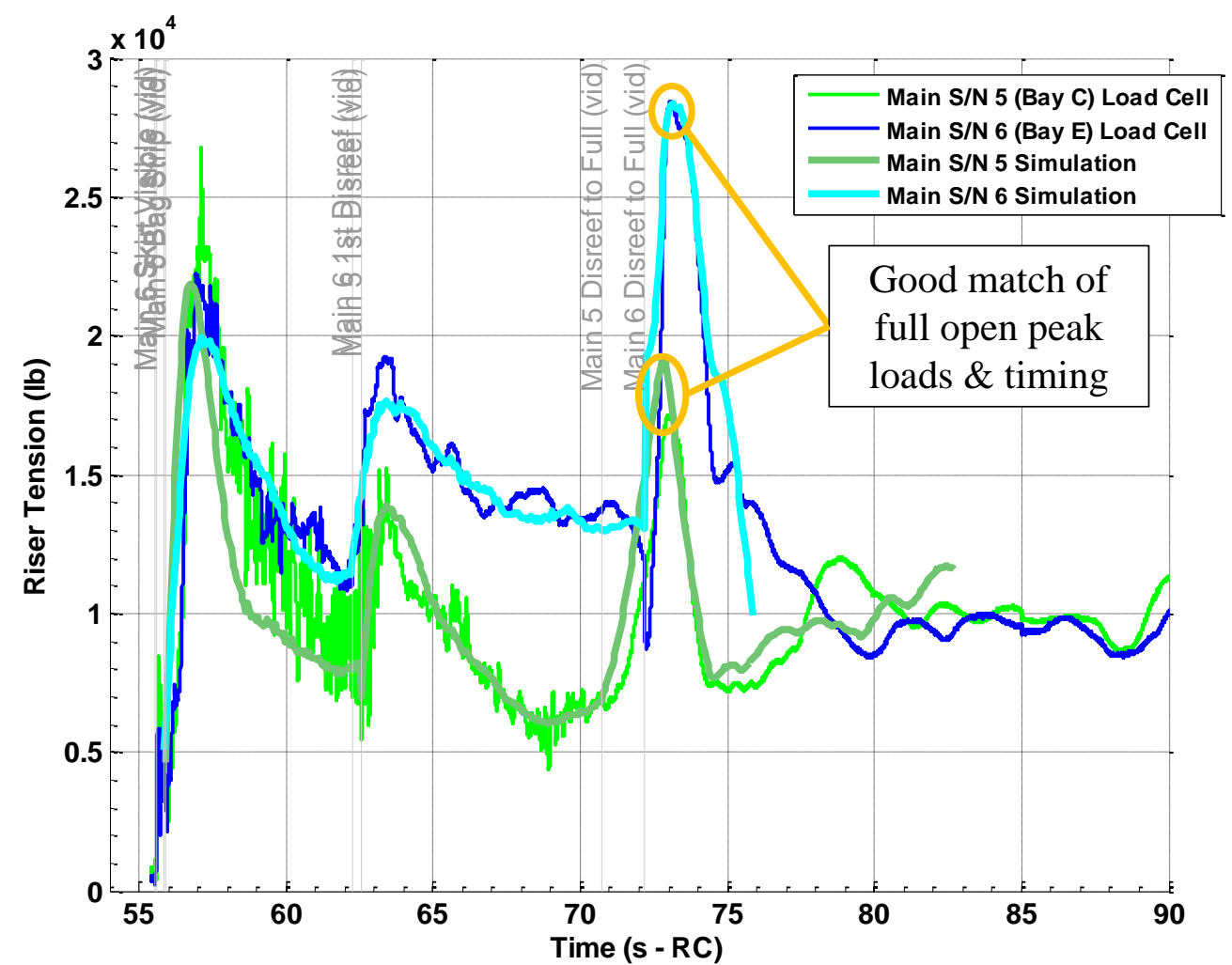

Figure 20. CDT-3-2 riser tension validation of peak load timing and magnitude $\left(K_{a e}=0\right)$.

In order to determine the sensitivity to apparent mass terms, the data reduction and simulation script was re-run for varying $\mathrm{K}_{\mathrm{ae}}$ values of $0.1,0.25,0.5,1.0$, and 2.0. Value of 0.1 and 0.25 (indicating that apparent mass is always $10 \%$ or $25 \%$ of enclosed mass) had little effect on the resulting simulated riser tension. As $\mathrm{K}_{\mathrm{ae}}$ increased, the total added mass increased and the inferred drag area decreased, such that the sum of all terms was equal to measured riser tension. At about $\mathrm{K}_{\mathrm{ae}}=0.5$, the total estimated added mass for the lead canopy (Main S/N 6) exceeds the peak measured riser tension, making it impossible to properly solve for drag area. The lagging canopy (Main S/N 5) did not encounter such a discrepancy until $\mathrm{K}_{\mathrm{ae}}$ exceeded about 1.4, indicating that apparent mass is dependent on canopy shape.

American Institute of Aeronautics and Astronautics 


\section{B. CDT-3-4}

CDT-3-4 was a 3-Main test where one of the canopies skipped second stage via a pre-cut reefing line. ${ }^{26}$ One of the non-skipping canopies was almost always obscured while the other was visible in the first stage and full open. The 3D models are compared to the images in Figure 21. Due to the non-skipping canopies being crowded out, only data on the skipped-stage parachute, Main S/N 4, are available during the skipped stage.
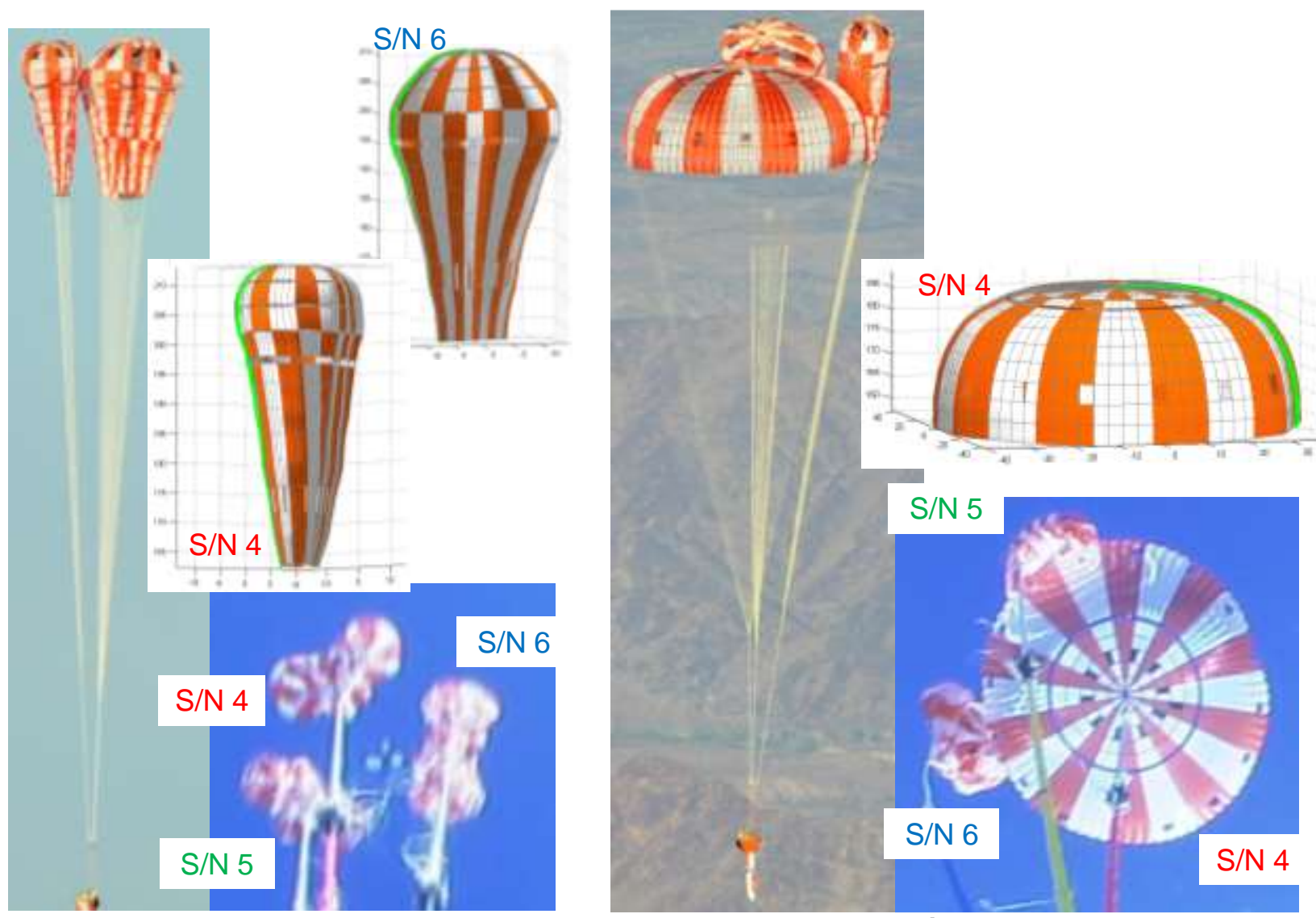

Figure 21. CDT-3-4 selected 3-D canopy models of $1^{\text {st }}$ stage and skipped $2^{\text {nd }}$ stage. 
The computed perimeter is plotted in Figure 22. The first stage perimeter for $\mathrm{S} / \mathrm{N} 4$ is consistently larger than the known reefing line length, perhaps indicating a bias in the scale factor used in the side view photo. Although the frequency of chase photos was limited, the data make a good transition to the KX photogrammetric results after each parachute disreefs to full open.

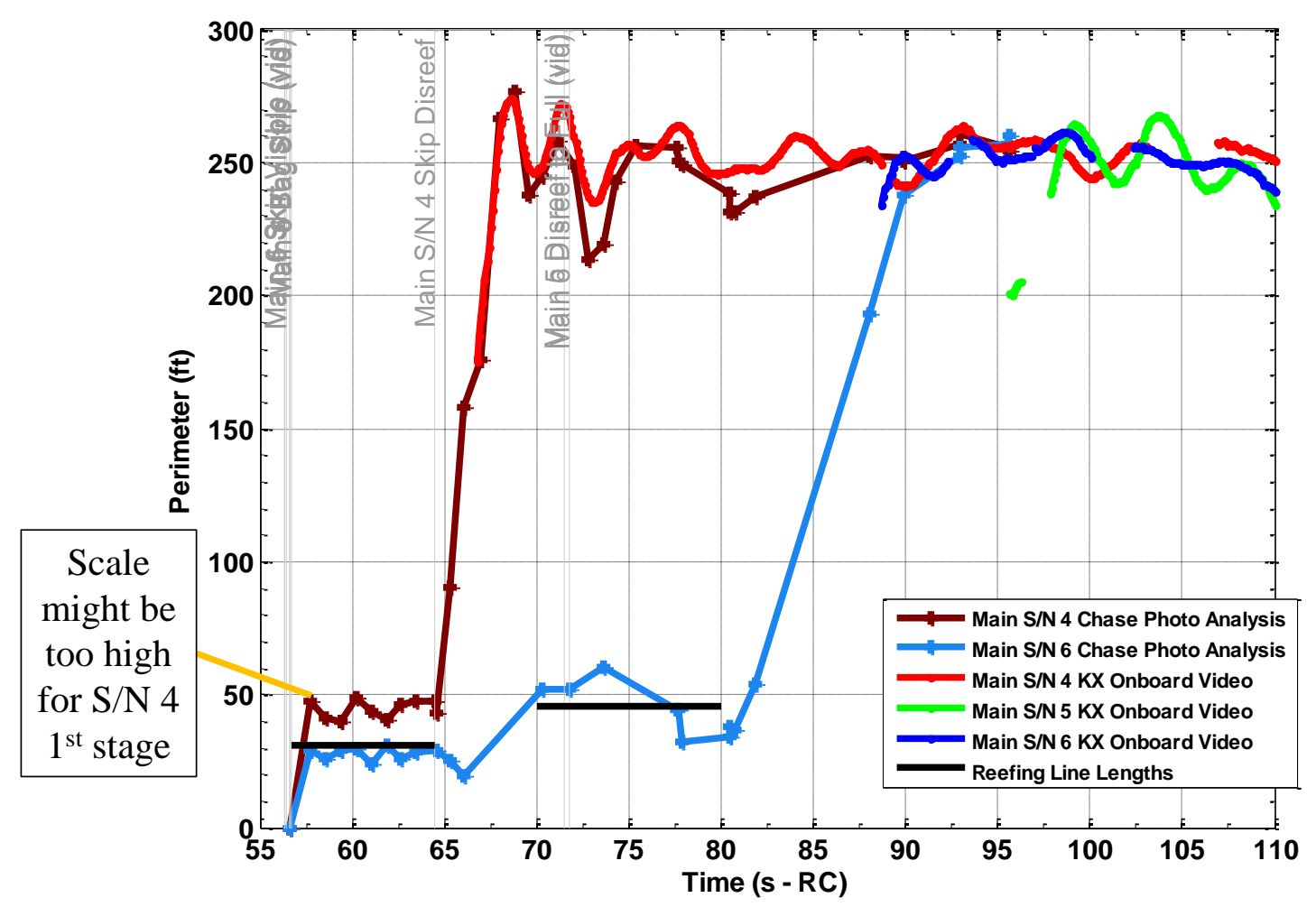

Figure 22. CDT-3-4 skirt perimeter.

American Institute of Aeronautics and Astronautics 
The enclosed volume has a linear trend with projected area, as shown in Figure 23. This trend is consistent with all CPAS tests analyzed to date. Because the chase photo imagery is limited, this relationship allows for the use of KX projected area data to be transformed into volume data near the time of full open of each canopy.

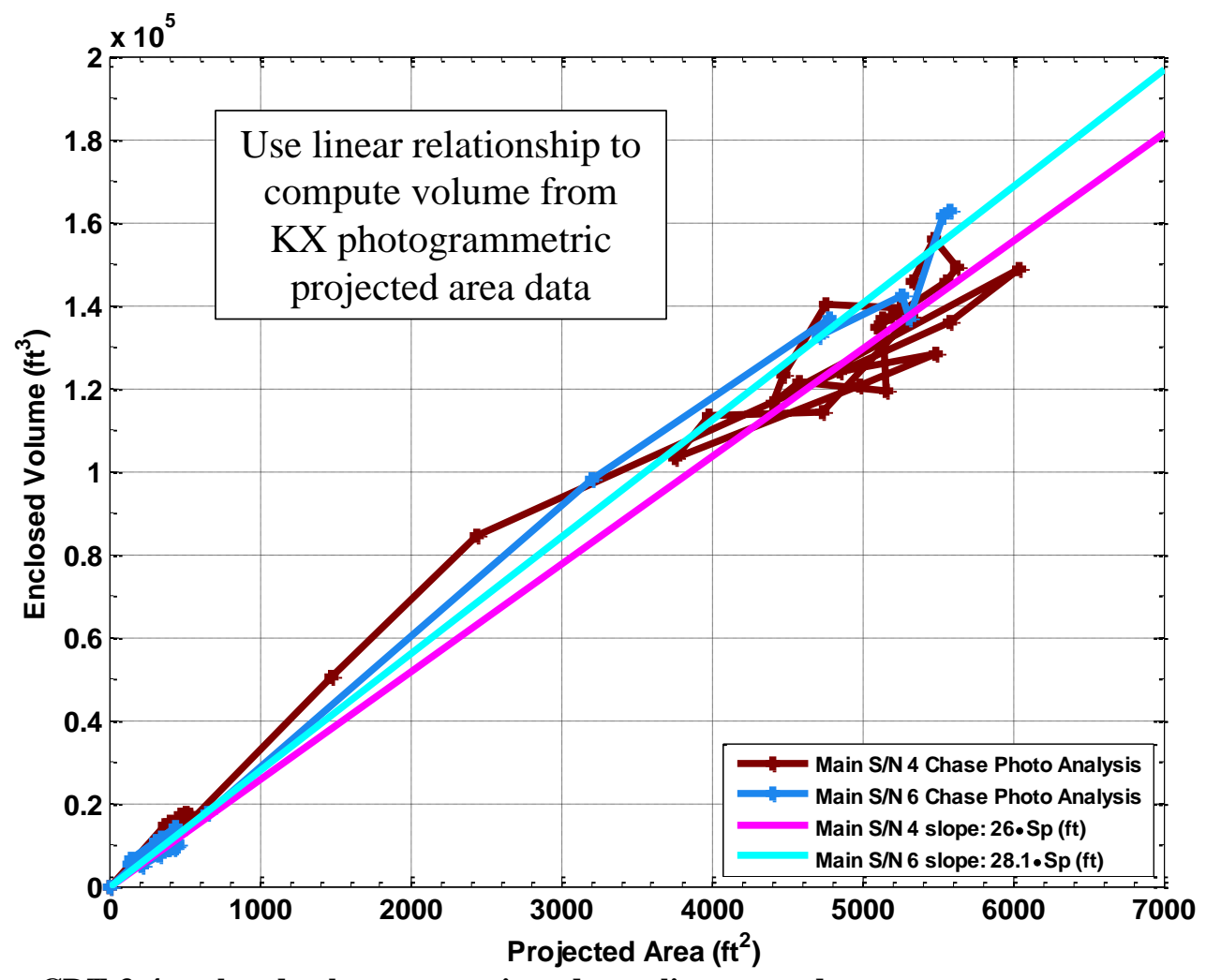

Figure 23. CDT-3-4 enclosed volume vs. projected area linear trends. 
The early chase photo-based projected area data were combined with later KX data to create composite projected area data time histories. These are plotted as pink and light blue circles in Figure 24. This also allows for using the more accurate KX data during later oscillatory periods.

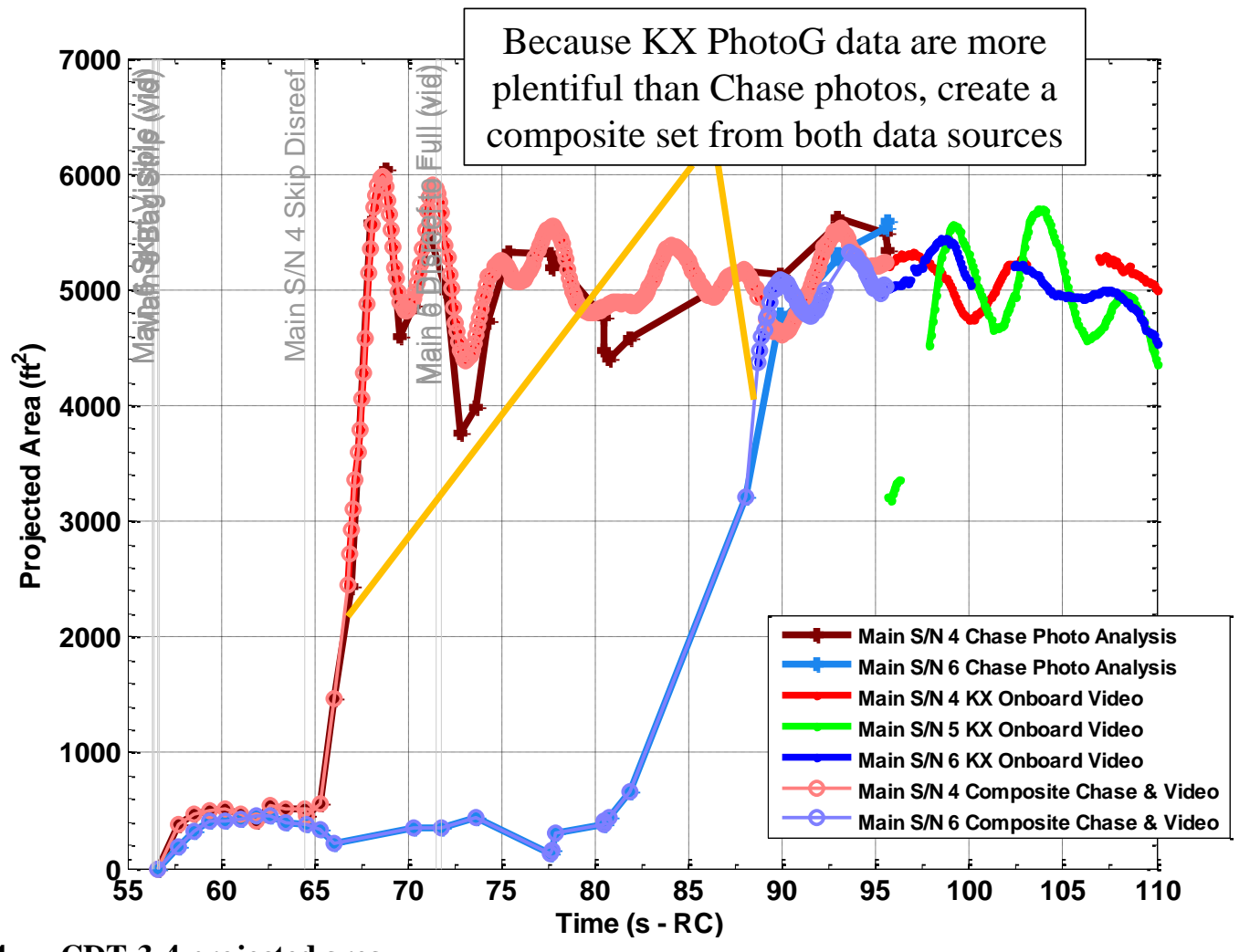

Figure 24. CDT-3-4 projected area. 
The directly measured enclosed volume data are compared with the inferred composite data in Figure 25 . The volume vs. time curves were fit with third order polynomials for all the stages of Main S/N 4 and S/N 6 .

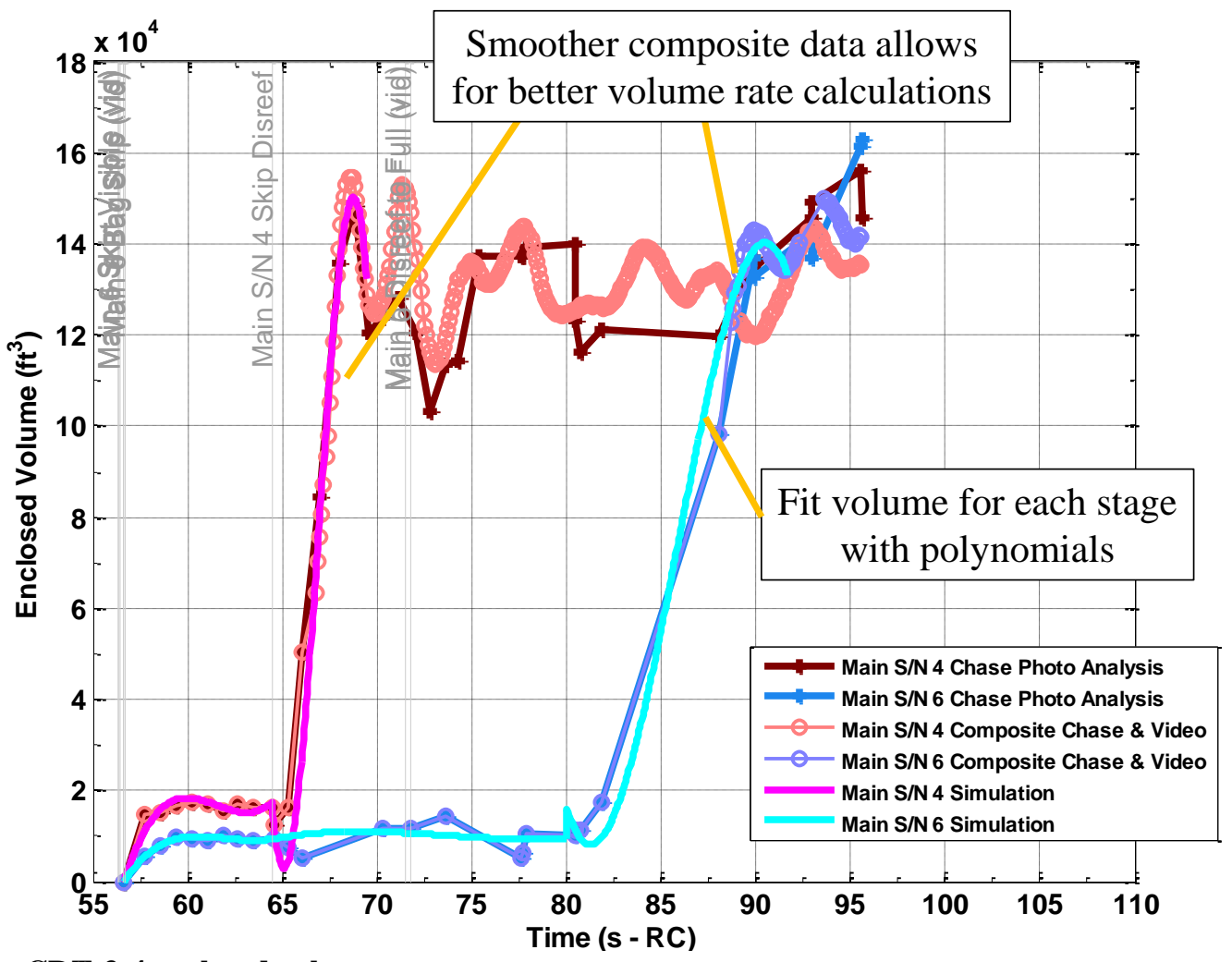

Figure 25. CDT-3-4 enclosed volume. 
The directly measured enclosed volume data are compared with the inferred composite data in Figure 26.

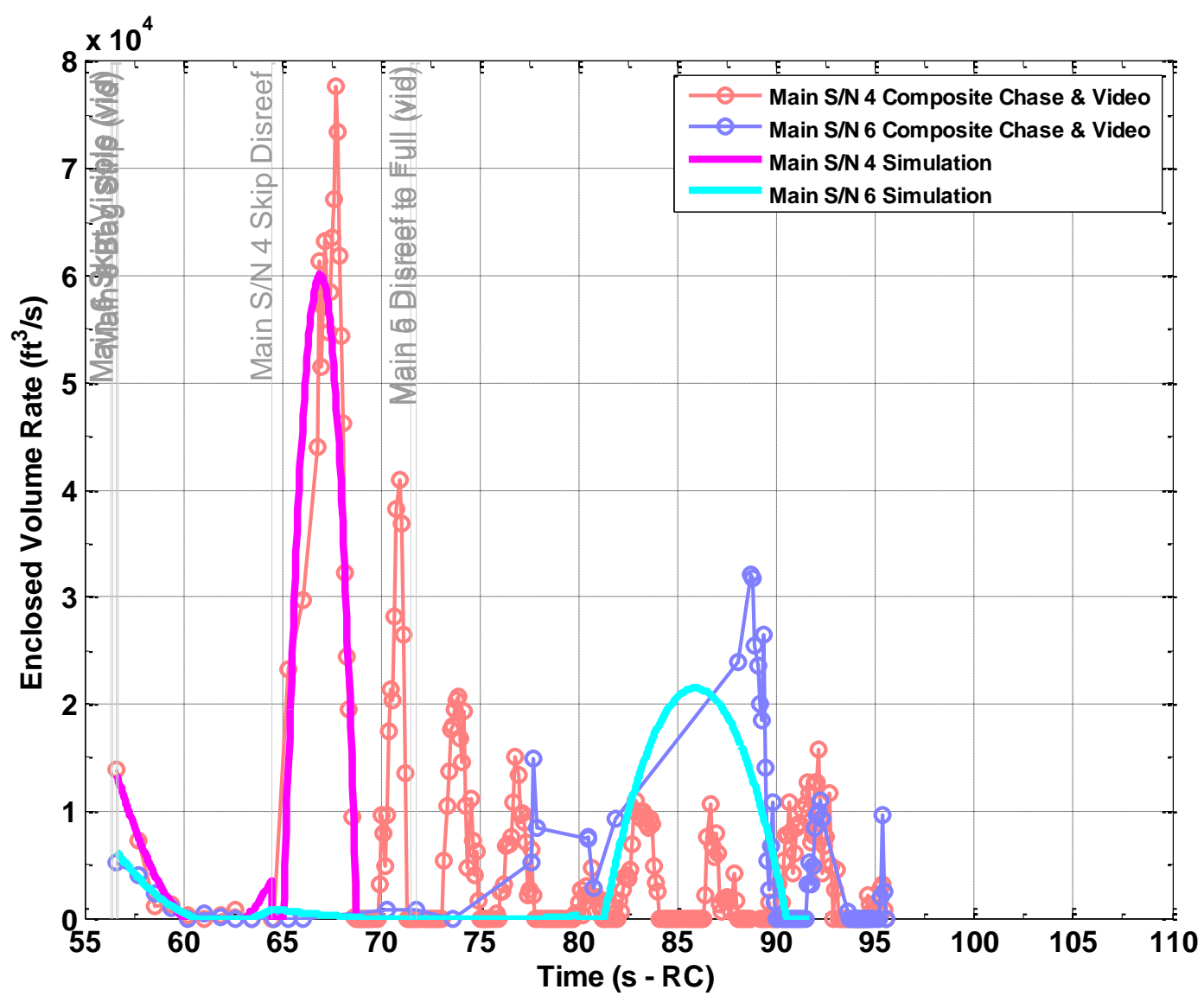

Figure 26. CDT-3-4 enclosed volume rate. 
From there, analysis of each load term proceeded as in the previous example. The sum of each of the computed load components are compared with the measured riser tensions in Figure 27. As expected, there is a significant peak in added mass load coincident with the measured peak riser tension in the skipped second stage. The difference between the measured riser tension and computed load is assumed to be exclusively due to drag area growth.

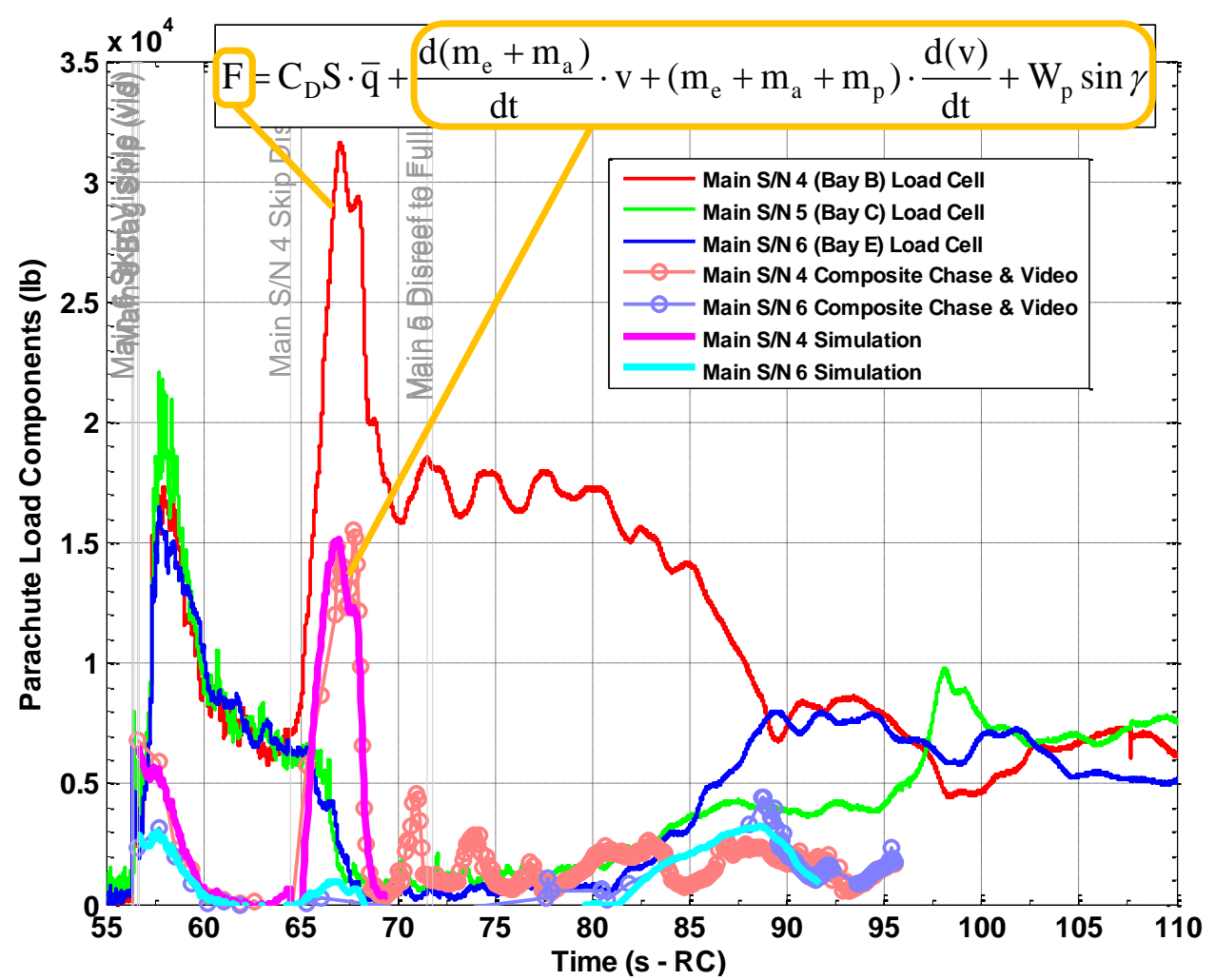

Figure 27. CDT-3-4 parachute load components compared with riser tension. 
The resulting drag area vs. volume conversion plot is presented in Figure 28. The data are again matched with quadratic curves. The curves for first stage (inset) are much smaller than the full open data. Oscillatory data after full open are not included in the matching process.

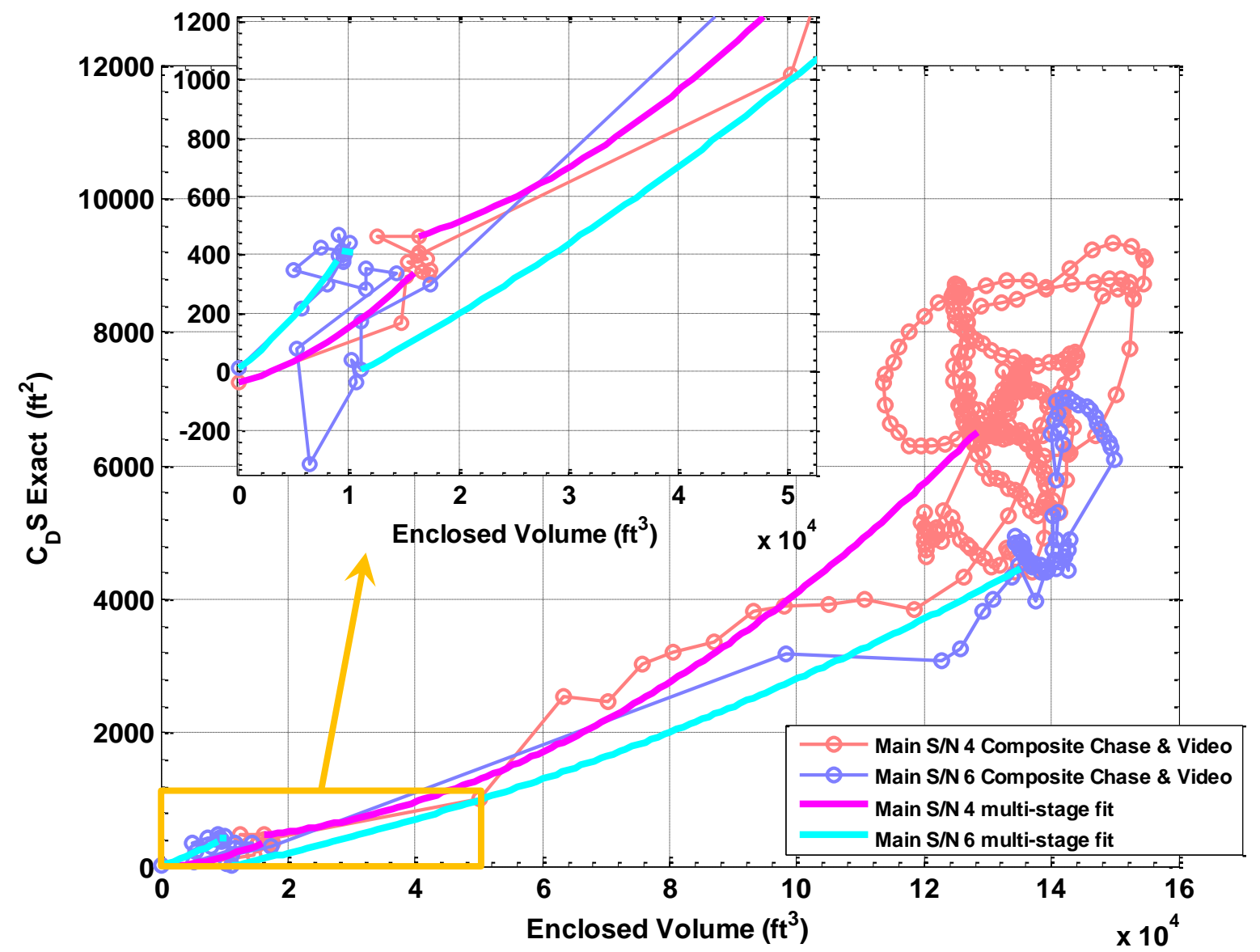

Figure 28. CDT-3-4 drag area vs. enclosed volume.

The drag areas for both simulated canopies were then computed using the look-up table. Simulated riser tension are compared with the measured data in Figure 29. Again, the peak inflation timing and magnitude are an acceptable match.

American Institute of Aeronautics and Astronautics 


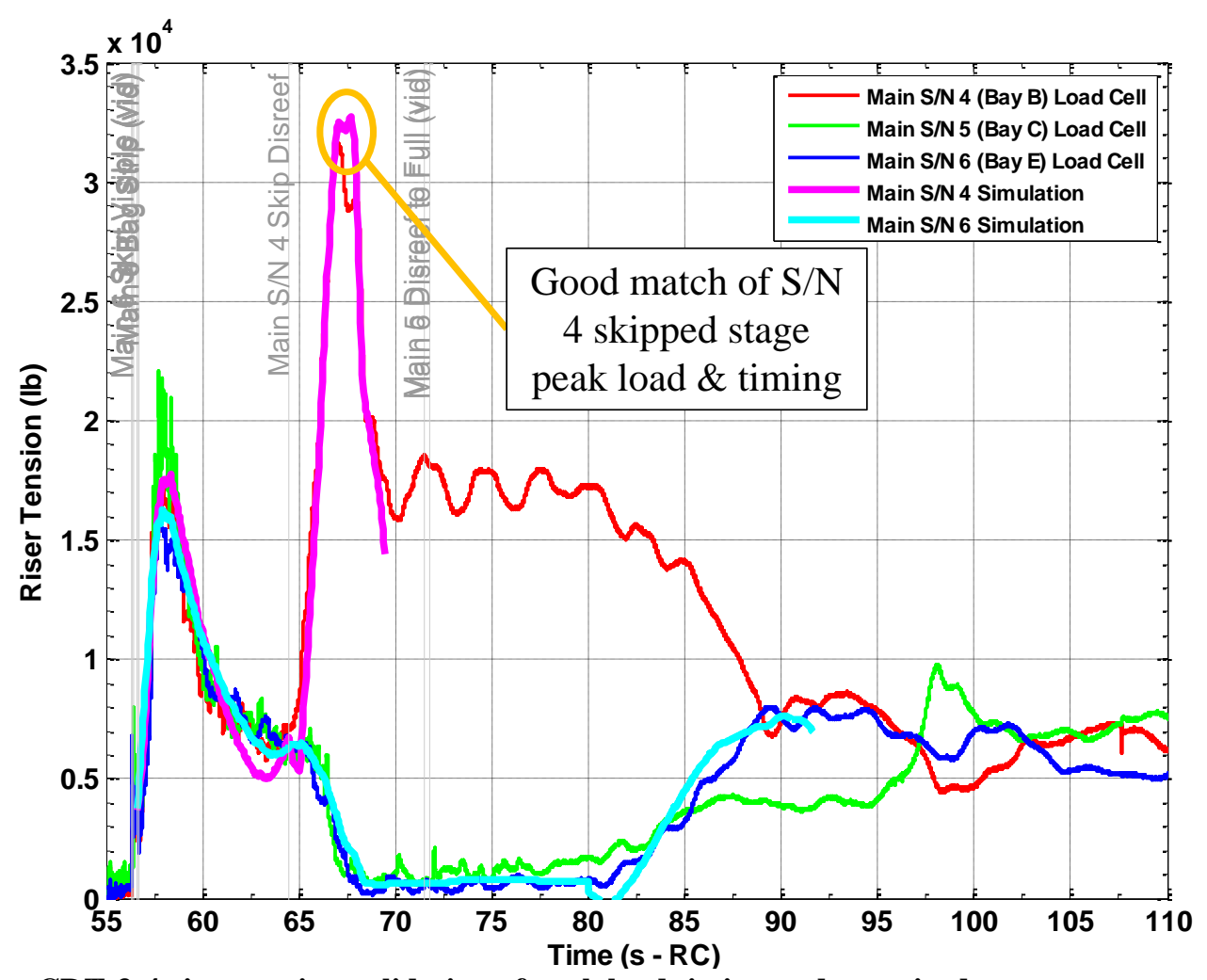

Figure 29. CDT-3-4 riser tension validation of peak load timing and magnitude.

As with the previous test, small increases to the amount of apparent mass had little effect on matching the measured riser loads. This was the case until $\mathrm{K}_{\mathrm{ae}}$ increased to about 0.6, at which point the simulated added mass matched the riser load, leading to the physically impossible situation of zero drag area.

\section{Conclusion}

The current CPAS simulation tool (FAST) generally matches the peak load magnitude, but with early timing, implying a flaw in the added mass model. Examination of the current added mass algorithm shows many undocumented features which may be problematic in extreme conditions.

A method was developed to describe the parachute inflation state using time-varying volume data, unlike traditional parachute simulation methods which calculate drag area growth based on empirical data. Volume data were obtained from high quality imagery of chase photos and upward-looking HD video of CPAS Main $116 \mathrm{ft} \mathrm{D}_{\mathrm{o}}$ ringsail canopies in clusters (described in a companion paper). The volume and volume rate data were then combined with best estimate atmospheric and vehicle state data to estimate parachute added mass components. When the sum of the load components are subtracted from measured riser tension, the parachute drag can be isolated. Drag area is modeled as a function of parachute volume.

The curve fits were then combined with interpolated test data to simulate peak riser tensions, which match in both magnitude and timing. The reconstructions presented assumed that apparent mass due to viscosity was negligible, though additional data, such as CFD solutions for drag, could be used to better estimate this effect.

By matching data to polynomial functions, this volume method may be difficult to incorporate into Monte Carlo simulations. Further, the curve fits are very sensitive to the data selection end point, which is subjective. This study is a preliminary effort to generate a fully documented added mass model relevant to large ringsail canopies anchored to high quality modern data.

\section{Acknowledgments}

The author would like to thank Prof. Jean Potvin for his recommendations regarding canopy modeling techniques. Summer intern Sumeet Vadodkar was instrumental in developing the volume estimation method. The photogrammetric data from upward-looking cameras used for comparison were reduced by David Bretz and others with the JSC-KX Image Science \& Analysis Group. The author would also like to thank the photographers and chase

American Institute of Aeronautics and Astronautics 
aircraft operators from NASA-JSC, NASA-Armstrong Flight Research Center, and the Yuma Proving Ground, who have been responsive and accommodating in delivering quality visuals.

\section{References}

${ }^{1}$ Ray, E. and Morris, A. L., "Measurement of CPAS Main Parachute Rate of Descent," $21^{\text {st }}$ AIAA Aerodynamic Decelerator Systems Technology Conference and Seminar, Dublin, Ireland, May 2011, AIAA paper 2011-2545.

${ }^{2}$ Ray, E., "Reconstruction of Orion EDU Parachute Inflation Loads," $22^{\text {nd }}$ AIAA Aerodynamic Decelerator Systems Technology Conference, Daytona Beach, Florida, March 2013, AIAA paper 2013-1260.

${ }^{3}$ Ray, E., "Photographic Volume Estimation of CPAS Main Parachutes," (submitted for publication).

${ }^{4}$ Ray, E., "Reefing Line Tension in CPAS Main Parachute Clusters," $22^{\text {nd }}$ AIAA Aerodynamic Decelerator Systems Technology Conference, Daytona Beach, Florida, March 2013, AIAA paper 2013-1393.

5 Ray, E. and Machín, R. A., "Pendulum Motion in Main Parachute Clusters," $23^{\text {rd }}$ AIAA Aerodynamic Decelerator Systems Technology Conference, Daytona Beach, Florida, March 2015, AIAA paper 2015-2138.

${ }^{6}$ Ray, E., Bretz, D. R., and Morris, A. L., "Photogrammetric Analysis of CPAS Main Parachutes," $21^{\text {st }}$ AIAA Aerodynamic Decelerator Systems Technology Conference and Seminar, Dublin, Ireland, May 2011, AIAA paper 2011-2538.

${ }^{7}$ Ray, E. and Bretz, D. R., "Improved CPAS Photogrammetric Capabilities for Engineering Development Unit (EDU) Testing," $22^{\text {nd }}$ AIAA Aerodynamic Decelerator Systems Technology Conference, Daytona Beach, Florida, March 2013, AIAA paper 20131258.

${ }^{8}$ Kidane, B. A., "Parachute Drag Area Using Added Mass as Related to Canopy Geometry," $20^{\text {th }}$ AIAA Aerodynamic Decelerator Systems Technology Conference and Seminar, Seattle, Washington, May 2009, AIAA paper 2009-2942.

${ }^{9}$ Morris, A. L., Bledsoe, K. J., Fraire, U., et al., "Summary of CPAS Gen II Testing Analysis Results," $21^{\text {st }}$ AIAA Aerodynamic Decelerator Systems Technology Conference and Seminar, Dublin, Ireland, May 2011, AIAA paper 2011-2585.

${ }^{10}$ Corwin, B., "Chute Modeling Background: UD233," IPT Presentation, Analysis IPT, 18 Feb. 2010.

${ }^{11}$ Cuthbert, P., "Decelerator System Simulation (DSS) Version 312," June 2010, NASA, Houston, TX.

12 Taylor, A. and Murphy, E., "The DCLDYN Parachute Inflation and Trajectory Analysis Tool - An Overview," $18^{\text {th }}$ AIAA Aerodynamic Decelerator Systems Technology Conference and Seminar, Munich, Germany, May 2005, AIAA Paper 2005-1624.

${ }^{13}$ Fraire, U., Dearman, J., and Morris, A., "Proposed Framework for Determining Added Mass of Orion Drogue Parachutes," $21^{s t}$ AIAA Aerodynamic Decelerator Systems Technology Conference and Seminar, Dublin, Ireland, May 2011, AIAA paper 20112546.

${ }^{14}$ Romero, L. and Ray, E., "Application of Statistically Derived CPAS Parachute Parameters," ," $22^{\text {nd }}$ AIAA Aerodynamic Decelerator Systems Technology Conference, Daytona Beach, Florida, March 2013, AIAA paper 2013-1266.

15 NovAtel, Inc., "SPAN-SE," NovAtel, Inc. web site [online], July 2012, URL: http://www.novatel.com/assets/Documents/Papers/SPAN-SE.pdf [cited 10 October2016].

16 NovAtel, Inc., "HG1700 SPAN," NovAtel, Inc. web site [online], 2008, URL: http://www.novatel.com/assets/Documents/Papers/HG1700_SPAN62.pdf [cited 10 October 2016].

17 NovAtel, Inc., "NovAtel Inertial Explorer," NovAtel, Inc. web site [online], URL: http://www.novatel.com/products/software/inertial-explorer [cited 10 October 2016].

18 Potvin, J. and McQuilling, M., "The Bi-model: Using CFD in simulations of slowly-inflating low-porosity hemispherical parachutes," $21^{\text {st }}$ AIAA Aerodynamic Decelerator Systems Technology Conference and Seminar, Dublin, Ireland, May 2011, AIAA paper 2011-2542.

19 Tezduyar, T. E., "Special Space-Time FSI Techniques for Spacecraft Parachutes," Team for Advanced Flow Simulation and Modeling (T*AFSM) web site [online], URL: http://www.tafsm.org/PROJ/AS/j175STFECCFSIP/ [cited 10 October 2016].

${ }^{20}$ Moorman, C. J., "Fluid-Structure Interaction Modeling of the Orion Spacecraft Parachutes," M.S. Thesis, Rice University, Houston, Texas, April 2010.

${ }^{21}$ Christopher, J. D., "Computational Aerodynamics Modeling of the Reefed Stages of Ringsail Parachutes," M.S. Thesis, Rice University, Houston, Texas, April 2009.

22 "Performance of and Design Criteria for Deployable Aerodynamic Decelerators," US Air Force Flight Dynamics Laboratory, Ohio. Technical Report ASD-TR-61-579, December 1963,pg. 155.

${ }^{23}$ Heinrich, H. G. and Noreen, R. A., "Analysis of Parachute Opening Dynamics with Supporting Wind Tunnel Experiments,” $2^{\text {nd }}$ AIAA Aerodynamic Deceleration Systems Conference, El Centro, California, September 1968, AIAA paper 68-924.

${ }^{24}$ Yavus, T. and Cockrell, D. J., "Experimental Determination of Parachute Apparent Mass and Its Significance in Predicting Dynamic Stability," $7^{\text {th }}$ AIAA Aerodynamic Decelerator and Balloon Technology Conference, San Diego, California, October 1981, AIAA paper 81-1920.

${ }^{25}$ Ray, E., "A Symmetric Time-Varying Cluster Rate of Descent Model," 23rd AIAA Aerodynamic Decelerator Systems Technology Conference, Daytona Beach, Florida, March 2015, AIAA paper 2015-2137.

${ }^{26}$ Varela, J. G., and Ray, E., "Skipped Stage Modeling and Testing of the CPAS Main Parachutes," 22 nd AIAA Aerodynamic Decelerator Systems Technology Conference, Daytona Beach, Florida, March 2013, AIAA paper 2013-1257.

American Institute of Aeronautics and Astronautics 